\title{
Bioprocess Optimization of Glutathione Production by Saccharomyces Boulardii: Biochemical Characterization of Glutathione Peroxidase
}

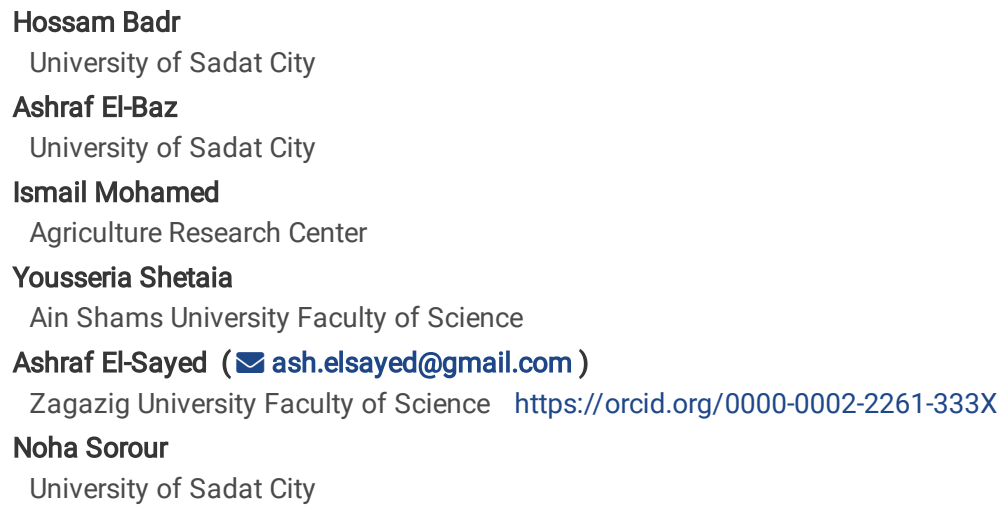

Version of Record: A version of this preprint was published at Archives of Microbiology on September 27th, 2021. See the published version at https://doi.org/10.1007/s00203-021-02584-0. 


\section{Abstract}

The well-known probiotic GRAS Saccharomyces boulardii (CNCM I-745) was used for the first time to produce glutathione (GSH). The culture conditions affecting GSH biosynthesis were screened using a Plackett-Burman design (PBD). Analyzing the regression coefficients for 12 tested variables; 6 of them, including yeast extract, glucose, peptone and cysteine; temperature and agitation rate had a positive significant effect on GSH production with a maximum production of $192 \mathrm{mg} / \mathrm{L}$. The impact of addition time of cysteine was investigated in 19 experiments during the growth time course (0-36 h), the best addition time was $8 \mathrm{~h}$ post-inoculation producing $235 \mathrm{mg} / \mathrm{L}$ of GSH. The most significant variables were further explored at 5-levels using Central Composite Rotatable Design (CCRD), giving a maximum production of GSH (552 mg/L). Using baffled flasks, the GSH was increased to $730 \mathrm{mg} / \mathrm{L}$, i.e 1.32 -folds increment than obtained using CCRD. The two rate-limiting genes of GSH biosynthesis " $\gamma$-glutamyl cysteine synthetase ( $g$ sh 1) and GSH-synthetase (gsh2) were amplified and sequenced to validate the GSH biosynthetic potency of S. boulardii. The sequences of genes showed $99 \%$ similarity with gsh 1 and gsh2 genes of $S$. cerevisiae. Glutathione peroxidase was purified and characterized from S. boulardii with molecular mass and subunit structure of $80 \mathrm{kDa}$ and $35 \mathrm{kDa}$ as revealed from native and SDS-PAGE, ensuring its homodimeric identity. The activity of GPx was reduced by 2.5 -folds upon demetallization confirming its metalloproteinic identity. The enzyme was strongly inhibited by hydroxylamine and DTNB, ensuring the implication of surface lysine and cysteine residues on the enzyme active site domains.

\section{Introduction}

During the last decades, biomaterials, fine chemicals, nutraceuticals, nanomaterials, and pharmaceutically relevant compounds have become increasingly biosynthesized by different microorganisms (El-Baz et al., 2011, 2016; 2018; Cui et al., 2019; Hassan et al., 2019). Glutathione (Y-glutamyl-L-cysteinyl-glycine) is non-protein-thiol containing tripeptide; which is widely distributed in living organisms, and mainly in eukaryotic cells (Meister and Anderson, 1983; Lienkamp et al., 2020). Glutathione (GSH) is an essential molecule for cells in the protection mechanisms against UV, xenobiotics, and heavy metals (Penninckx, 2002; Lorenz et al., 2016; Lienkamp et al., 2020). GSH is an essential bioactive tripeptide widely used in food, medicine, and other industries (Cui et al., 2019; Dan et al., 2020). In humans, GSH deficiency has been linked to numerous disorders, such as, cardiovascular diseases, pulmonary diseases, liver cirrhosis, diabetes, gastrointestinal, and pancreatic inflammations, immune, aging, and neurodegenerative diseases (Wu et al., 2004; Ballatori et al., 2009). Another major use of GSH is its use as a supplementation in GSH-deficient disorders observed in liver diseases, cystic fibrosis, Alzheimer's disease, Parkinson's disease, age-related disorders, and HIV infection (Ballatori et al., 2009; Saing et al., 2016). Other uses of GSH are in various acceptable formulations such as, emulsifiers, anti-aging and moisturizers for skin care and anti-sun products (Perricone et al., 2011). In a recent study, Khullar and Reddy, (2020) investigated the potential use of the ecto-mycorrhizal fungus (Hebeloma cylindrosporum) in the detoxification of Arsenic (As), As was accumulated intracellularly by the fungus, and the production of GSH was induced, thus, this fungus was recommended to be used for many bioremediation applications (Khullar and Reddy, 2020). To date, the organisms of choice for efficient production of GSH are the yeasts, especially S. cerevisiae and Candida utilis (Wei et al., 2003; Santos et al., 2007; Xiong et al., 2009; Liang et al., 2010; Wang et al., 2012; Lorenz et al., 2016; Prima et al., 2017). Yeasts provide advantage such as, their ability for fast growing to high cell densities in low-price media (Bachhawat et al., 2009). In the early past, genetic modified bacteria e.g. Escherichia coli, was successfully used for GSH production (Wang et al., 2015). Recently, Cui et al. (2019) reported that the engineered strain E. coli JM109 produced 24 mM GSH, using fed-batch fermentation in 5-L bioreactor, and the yield of GSH was improved by $17.3 \%$ as compared to the control strain. However, consumers usually do not accept the use of GMOs, especially in food. GSH is produced industrially by S. cerevisiae in high concentration, which is generally recognized as safe (GRAS) (Li et al., 2004; Prima et al., 2017; Hong et al., 2019). However, it is worthwhile to search for a novel GSH producer GRAS-microorganism. Interestingly, Saccharomyces boulardii is a non-pathogenic yeast strain widely prescribed for adults and children as a biotherapeutic agent (McFarland and Berncasconi, 1993). S. boulardii is an a-sporogeneses yeast that grow well at $37^{\circ} \mathrm{C}$ and $\mathrm{pH} 2.0$, thus had better heat/acid tolerance (Du et al., 2012). In addition, S. boulardii, was used as "probiotic" in animal feeding, and has been effective for reducing pathogens and their corresponding toxins concentration, strengthening the microbial balance, in addition to stimulating the immune system. S. boulardii is genetically very close to $S$. cerevisiae, however, it shows a very different behavior, particularly, in relation to growth yield and resistance to stresses, such as, temperature and acidic conditions, which are important features for any microorganism used in probiotic applications (Fietto et al., 2004). Lately, Hong et al. (2019) stated that the probiotic S. cerevisiae BOF (S. boulardii based product) can produce (5.1 mg/g dry basis) of GSH. GSH is synthesized in two consecutive ATP dependent reactions (Meister and Anderson, 1983). Firstly, the dipeptide $\gamma$-glutamyl cysteine $(\mathrm{y}-\mathrm{GC})$ is synthesized from L-cysteine and L-glutamic acid by $\mathrm{Y}$-glutamyl cysteine synthetase (EC 6.3.2.2, GSHI). In the second step, glycine is added to the C-terminal site of Y-GC by GSH synthetase (EC 6.3.2.3, GSH.II) to form GSH. Both enzymes have been purified from several biological sources and their corresponding genes have been cloned from yeast (Mutoh et al., 1991 and 1995; Shi et al., 2020) bacteria (Gushima et al., 1984; Ohtake et al., 1989; Cui et al., 2019), and animal tissues (Habenicht et al., 1993; Huang et al., 1995; Wang et al., 2018). The optimization and control of the production process for GSH have been investigated, showing that the temperature, agitation rate, and the pH are the most significant factors affecting its production (Santos et al., 2007). Furthermore, the addition of amino acids such as, cysteine, glycine, glutamate, and serine have increased the yield of GSH by 2.67-fold as compared with control medium free from theses amino acids (Wen et al., 2004). Furthermore, Cha et al. (2004) reported that by the optimization of concentrations of glucose, yeast extract, $\mathrm{K}_{2} \mathrm{HPO}_{4}$, and cysteine in the medium; the productivity of GSH was increased 2.27-fold as compared with the basal medium.

For the aforementioned reasons, the main objective of the present work was to optimize the production of GSH using the GRAS S. boulardii for the first time, where 12 environmental and nutritional factors were screened using PBD, in conventional Erlenmeyer flasks. After analyzing the design and determining the significant factors, CCRD has been applied to establish the response surface, fitting the model, and forecasting the optimum conditions for the biosynthesis of $\mathrm{GSH}$. To maximize the production of GSH, a comparison between conventional Erlenmeyer and baffled flasks was investigated, with all the optimum conditions detected in CCRD. The two responsible genes for the biosynthesis of GSH (gsh1 and gsh2) were sequenced to validate the potency of GSH biosynthesis, as well as, glutathione peroxidase (GPx) was purified and biochemically characterized.

\section{Materials And Methods}




\subsection{Chemicals}

Reduced L-GSH and Alloxan were obtained from Sigma-Aldrich Inc. (Sigma-Aldrich, St. Louis, MO, USA). Dibasic sodium phosphate and glucose were obtained from ADWIC (CAIRO, Egypt). Yeast extract, agar-agar and peptone were obtained from SAS chemical Co., (MUMBAI, India). Malt extract, Glycine, L-Cysteine and L-Glutamic acid were bought from LOBA Chemie (MUMBAI, India). All solutions were prepared using deionized distilled water.

\subsection{Strains, media, and plasmids}

The strain S. boulardii was isolated from "Florastor ${ }^{\circledR}$ ", a commonly commercialized product (xxx). Under aseptic conditions, in a laminar air-flow (Heraeus, Germany), the contents of one capsule was dispensed into $500 \mathrm{~mL}$ Erlenmeyer flask containing $100 \mathrm{~mL}$ of sterilized Yeast Malt Peptone (YMP) broth medium with the following components (g/L); Yeast Extract 3.0, Malt Extract 3.0, Peptone 5.0 and Dextrose 10.0, pH was adjusted to $6.5 \mathrm{using} 1 \mathrm{~N} \mathrm{NaOH} / 1 \mathrm{M} \mathrm{HCl}$, then mixed well and incubated in shaking incubator (New Brunswick ${ }^{\mathrm{TM}}$, Innova ${ }^{\circledR} 43$ ) at $170 \mathrm{rpm}$ and $30^{\circ} \mathrm{C}$ for $24 \mathrm{~h}$. S. boulardii was spread on YMP agar plates and incubated for $24 \mathrm{~h}$, the developed pure colonies were examined, transferred, maintained on YMP agar slants at $4{ }^{\circ} \mathrm{C}$, and renewed every 30 days. Escherichia coli JM109 was used as the recipient strain for the recombinant plasmid and it was grown in Luria-Bertani medium supplemented with $100 \mu \mathrm{g} / \mathrm{mL}$ ampicillin. pGEM-T easy vector (Promega) was used as a cloning vector for various PCR products generated during this study.

\subsection{DNA extraction and PCR amplification of $g s h 1$ and $g s h 2$}

Genomic DNA was extracted from $24 \mathrm{~h}$ pure S. boulardii culture using the Yeast DNA Extraction Kit (Thermo Scientific ${ }^{\mathrm{TM}}$ Cat. No. 78870) according to the manufacturer's instructions. The DNA quality was checked by $1 \%$ agarose gel as well as spectrophotometrically (at $\boldsymbol{\lambda}_{\mathbf{2 6 0}}$ and $\boldsymbol{\lambda}_{\mathbf{2 8 0}} \mathrm{nm}$ ). Gsh1 (Gene ID. 853344) encoding the $\gamma$-glutamyl cysteine synthetase ( $y$-GC) GCS EC 6.3.2.2), that catalyzes the reaction (to form $\gamma$-GC from L-glutamic acid and L-cysteine) and gsh2 (Gene ID. 854108) encoding GSH synthetase (GSH EC, 6.3.2.3), were amplified by PCR from the S. boulardii genomic DNA. The forward and reverse primers used for amplification of gsh 1 were 5'-GACTAGTATGGGACTCTT AGCTTTGGGC-3' and 5'TCAGATCTTTAACATTTGCTTTCTATTGAAGGCTTATTT-3', respectively, whereas, the primers for amplification of gsh2 were 5'ACGCGTCGACATGGCACA CTATCCACCTTCC3' and 5'GG

CAGATCTCTAGTAAAGAATAATACTGTCCAAACATCC G-3', respectively (Yoshida et al., 2011). PCR was performed in a $50 \mu \mathrm{L}$ reaction volume containing 1X PCR buffer (10 mM Tris-HCl pH 8.3; $50 \mathrm{mM} \mathrm{KCl;} 2 \mathrm{mM} \mathrm{MgCl}{ }_{2}$ and $0.01 \%$ (w/v) gelatin), $250 \mu \mathrm{M}$ each of dGTP, dATP, dCTP and dTTP (dNTPs), 2.5 units of Taq DNA polymerases, 100 pmol of each primer and the DNA template. PCR reaction conditions were $94{ }^{\circ} \mathrm{C}$ for 4 min; 35 cycles of denaturation at $94{ }^{\circ} \mathrm{C}$.; annealing at $60^{\circ} \mathrm{C}$; and extension at $72^{\circ} \mathrm{C}$ for $50,60,120$ seconds, respectively, and finally followed by 7 min extension at $72{ }^{\circ} \mathrm{C}$. The amplified PCR product was visualized by electrophoresis on $1.5 \%(\mathrm{w} / \mathrm{v})$ agarose gel for confirmation of amplification. Purification of the PCR product was done using high pure PCR purification kit (Qiagen).

\subsection{Cloning, sequencing and phylogenetic analyses of gsh1 and gsh2}

The PCR products were purified using high pure PCR purification kit (Qiagen), and ligated into pGEM-T vector with T4 DNA ligase overnight at $4{ }^{\circ} \mathrm{C}$. The recombinant clones were transformed into E. coli JM109 competent bacteria according to the manufacturer's instructions. The amplicons of PCR were purified and sequenced using ABI PRISM Big Dye Terminator Cycle Sequencing Ready Reaction Kit (PE Applied Biosystem, USA) and the DNA sequencer ABI 310 Genetic Analyzer. The obtained sequence data were further analyzed using the BLAST tool of NCBI (Zhang et al., 2000). The obtained sequences of ( $g$ sh 1 ) and (gsh2) genes were BLAST searched non redundantly on the NCBI database, and aligned with ClustalW muscle algorithm, and the phylogenetic tree was constructed using MEGA5 neighbor-joining method with 1000 bootstrap replication (Tamura et al., 2011).

\subsection{In-Silico analysis of GSH sequence}

The sequence data were translated using ExPASy online translation tools (www.expasy.com). The six frames translation analysis was used for predicting the open reading frame (ORF). The open reading frames without stop codons for Y-glutamyl cysteine synthetase (gsh1) and GSH synthetase (gsh2) were selected for further bioinformatic analysis by protein BLAST The diversity of the sequence among the selected isolate was analyzed by multiple sequence alignment and comparative sequence analysis along with ( $g s h 1$ and gsh2) sequence of top ten NCBI protein alignment database using CLUSTAL W program.

\subsection{Experimental designs}

\subsubsection{Inoculum and shake-flask culture conditions}

Seed culture was prepared by inoculating $24 \mathrm{~h}$ old $\mathrm{S}$. boulardii slant into $250 \mathrm{~mL}$ YMP broth medium. The flask was incubated in shaking incubator at $30{ }^{\circ} \mathrm{C}$ and $170 \mathrm{rpm}$ for $24 \mathrm{~h}$. All Shake-flask experiments were performed in $250 \mathrm{~mL}$ Erlenmeyer flasks (baffled or unbaffled), each containing $50 \mathrm{~mL}$ of culture medium and inoculated with $10 \%(\mathrm{v} / \mathrm{v})$ of the seeding culture.

\subsubsection{Plackett-Burman experimental design and data analysis}

Plackett-Burman design (PBD) is an efficient tool to screen important variables among many factors with the least number of experiments (Plackett and Burman, 1946). In PBD, 12 variables including the glucose, peptone, malt extract, cysteine, glutamic, glycine, yeast extract; and temperature, initial pH, agitation rate, medium volume and incubation period were set in two levels; -1 and +1 for low and high levels, respectively. 4 of these variables (cysteine, glutamic, glycine, yeast extract) were investigated regarding to their GSH inducing properties. A GSH inducer was defined as a substance that can be biologically transformed to GSH. The arrangement of each experiment was generated by MINITAB ${ }^{\circledR} 17$ (Minitab Inc., PA, USA). All experiments were conducted in duplicate and their mean values of $\mathrm{GSH} \%, \mathrm{GSH}$ content $(\mathrm{g} / \mathrm{L})$ and cell dry weight (CDW) were taken as a response (Table 1$)$. A total of 44 experiments were conducted 
as the design was replicated. The analysis of variance (ANOVA) for the experimental data and the model coefficients were computed with MINITAB ${ }^{\circledR} 17$ statistical analysis tool kit (Equation 1).

\section{$\mathbf{Y}=\boldsymbol{\beta}_{0}+\Sigma \beta_{\mathbf{i}} \mathbf{x}$ (Equation 1)}

Where $Y$ is the predicted response; $\beta_{0}$ is the model constant; $\beta_{i}$ is the linear coefficient and $X_{i}$ is the independent variable.

\subsubsection{The effect of addition time of cysteine}

To investigate the impact of addition time of cysteine ( $5 \mathrm{mM}$ ); a total of 19 experiments were carried out at $0,2,4,6,8,10,12,14,16,18,20,22,24,26,28,30$, 32,34 and $36 \mathrm{~h}$ of growth, using PBD design (Experiment no. 5) to determine the best addition time for the biosynthesis of GSH.

\subsubsection{Central Composite Rotatable Design (CCRD)}

The significant factors affecting GSH production by S. boulardii, were identified using PBD as yeast extract, glucose, peptone, and cysteine concentrations as major independent variables. Based on these results, the experiment was further expanded to a Central Composite Rotatable Design (CCRD) to get the optimum levels of the tested variables leading to the maximum GSH production with fixing the temperature value and agitation rate at $31^{\circ} \mathrm{C}$ and $225 \mathrm{rpm}$ (Myers et al., 2016). Since the addition time of cysteine has an influential effect on both GSH and CDW, so the CCRD design was carried out twice, in the first one, cysteine was added at zero time; while in the second, it was added after $8 \mathrm{~h}$ of inoculation. The design matrix, variables, and their levels in coded units for both designs were listed in Table 1. All the experimental design, analysis of variance (ANOVA), and data analysis were performed using MINITAB ${ }^{\circledR} 17$ (Minitab Inc., PA, USA). The quality of fit of the polynomial model equation was expressed by the coefficient of determination $\left(R^{2}\right)$. These experiments were performed in duplicates and their mean values were given. A four-factor-five-level CCRD was employed, requiring 31 experiments. The design consists of 16 factorial, 8 axial and 7 central points. Both designs were carried out concomitantly to alleviate and minimize all sources of errors originating from handling and measurement systems. To predict the optimal point, a second-order polynomial function was fitted to correlate the relationship between the GSH content as a response and all the independent variables (Myers et al., 2016) (Equation 2).

\section{$Y=\beta_{0}+\beta_{1} X_{1}+\beta_{2} X_{2}+\beta_{3} X_{3}+\beta_{4} X_{4}+\beta_{12} X_{1} X_{2}+\beta_{13} X_{1} X_{3}+\beta_{14} X_{1} X_{4}+\beta_{23} X_{2} X_{3}+\beta_{24} X_{2} X_{4}+\beta_{34} X_{3} X_{4}+\beta_{11} X_{1}^{2}+\beta_{22} X_{2}^{2}+\beta_{33} X_{3}^{2}+\beta_{44} X_{4}^{2} \quad(E q u a t i o n ~ 2)$}

Where $Y$ is the predicted response; $\beta_{0}$ is the model constant; $X_{1}, X_{2}, X_{3}$ and $X_{4}$ are the independent variables; $\beta_{1}, \beta_{2}, \beta_{3}$ and $\beta_{4}$ are the linear coefficients; $\beta_{12}$, $\beta_{13}$, $\beta_{23}, \beta_{24}$ and $\beta_{34}$ are the cross product coefficients; and $\beta_{11}, \beta_{22}, \beta_{33}$ and $\beta_{44}$ are the quadratic coefficients.

\subsection{Cell Dry Weight (CDW) and Optical Density (OD)}

Yeast cultures were sampled periodically, and the cell biomass concentration was determined by the cell dry weight. Five milliliters of the growth culture were centrifuged at $5000 \mathrm{rpm}$ for $10 \mathrm{~min}$. and the pellet was washed twice with $5 \mathrm{~mL}$ saline solution $(0.9 \% \mathrm{NaCl})$, dried at $105^{\circ} \mathrm{C}$ until constant weight. For $\mathrm{OD}$ measurement, samples were withdrawn every $2 \mathrm{~h}$ and diluted appropriately with saline solution, then growth OD was assessed at $\boldsymbol{\lambda}_{600} \mathrm{~nm}$ spectrophotometrically. The glucose concentration was assayed by a glucose meter (accu-chek ${ }^{\circledR}$ active glucose meter system).

\subsection{Intracellular GSH assay}

Saccharomyces boulardii was incubated at $95^{\circ} \mathrm{C}$ for 20 minutes to release the $\mathrm{GSH}$ from the cells into the aqueous layer (Xiong et al., 2009). Cells were then removed by centrifugation at $5000 \mathrm{rpm}$ for $20 \mathrm{~min}$ and then the GSH content in the supernatant was assayed using Alloxan method as described by Wen et al. (2005). GSH reacts with Alloxan under the specified conditions of the experiment and its concentration was determined spectrophotometrically at $305 \mathrm{~nm}$. Briefly, $1 \mathrm{~g} / \mathrm{L}$ Alloxan was freshly prepared in $0.1 \mathrm{M} \mathrm{HCl}$ solution and stored in amber glass bottle, glycine $(0.1 \mathrm{M})$ was prepared using deionized water. Phosphate buffer $(\mathrm{pH} 7)$ was prepared by mixing equimolar solutions $(0.24 \mathrm{M})$ of $\mathrm{Na}_{2} \mathrm{HPO}_{4}$ and $\mathrm{NaH}_{2} \mathrm{PO}_{4}$ in deionized water. Standard reduced-GSH calibration curve $(0-200 \mathrm{mM})$ was prepared using GSH serially diluted with deionized water. The intracellular GSH content (mg/L) was calculated from the calibration curve (Linear Regression). Each of the GSH standard concentrations was mixed in a cuvette containing $3.5 \mathrm{~mL}$ of $0.24 \mathrm{M} \mathrm{NaHPO}_{4} / \mathrm{NaH}_{2} \mathrm{PO}_{4} \mathrm{buffer}$ and $0.5 \mathrm{~mL}$ of glycine $(0.1 \mathrm{M})$. One $\mathrm{mL}$ of Alloxan solution was added to initiate the reaction, left for 20 min, and then the absorbance was measured at 305 $\mathrm{nm}$. For sample analysis, $1 \mathrm{~mL}$ of tested sample was used instead the standard GSH. The reduced GSH content was calculated based on the following formula (Wang et al., 2012):

\section{Intracellular reduced GSH $(\%, \mathrm{~W} / \mathrm{W})=\mathrm{GSH}(\mathrm{g} / \mathrm{L}) * 100$ $\overline{\text { CDW (g/L) }}$}

\subsection{Glutathione peroxidase activity (GPx)}

The crude enzyme was extracted by pulverizing $\mathrm{S}$. boulardii ( $5 \mathrm{~g}$ fresh weight) in liquid nitrogen, dispensing in sterile extraction buffer $50 \mathrm{~mL}$ Tris- $\mathrm{HCl}$ ( $10 \mathrm{mM}$, pH 7.0) containing 1 mM PMSF, 1 mM EDTA and 1 mM 2-mercaptoethanol (ElMekawy et al., 2013; El-Sayed et al., 2016, 2019). The homogenate was

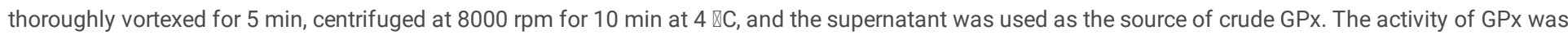
determined by 5,5'-dithiobis-2-nitrobenzoic acid (DNTB) (Ellman's reagent) (Rahman et al., 2007). Briefly, the reaction mixture 10 mM GSH, 1 mM EDTA, 390 $\mu \mathrm{M} \mathrm{H}_{2} \mathrm{O}_{2}$, dissolved in Tris- $\mathrm{HCl}(40 \mathrm{mM}, \mathrm{pH} 7.0)$ and $100 \mu \mathrm{L}$ enzyme preparation in $1 \mathrm{~mL}$ total volume. Blanks of enzyme and substrate were prepared. After incubation at $37{ }^{\circ} \mathrm{C}$ for $15 \mathrm{~min}$, the reaction was stopped by freezing at $-20{ }^{\circ} \mathrm{C}$ for $5 \mathrm{~min}$, amended with $100 \mu \mathrm{L}$ DTNB reagent and incubated for 10 min. The residual concentration of GSH (GSH-TNB adducts) was measured spectrophotometry at $412 \mathrm{~nm}$ (Tietze, 1969). One unit of glutathione peroxidase was

Page $4 / 20$ 
expressed by the amount of enzyme releasing $1 \mu$ mole of oxidized glutathione (GSSG) from reduced glutathione (GSH) as substrate per min per mg protein under standard assay. The protein content of the enzyme was determined by Bradford's reagent using bovine serum albumin as standard (Bradford, 1976).

\subsection{Purification and molecular subunit structure of $S$. boulardii GPx}

S. boulardii was grown on the nutritionally optimized media for GSH production as described above, incubated at standard conditions. After growth, the yeasts pellets $(20 \mathrm{~g})$ were collected, washed by sterile saline and pulverized in liquid nitrogen, dispensed in $50 \mathrm{~mL}$ Tris- $\mathrm{HCl}(10 \mathrm{mM}, \mathrm{pH} 7.0)$ with $1 \mathrm{mM} \mathrm{PMSF}, 1 \mathrm{mM}$ EDTA and 1 mM 2-mercaptoethanol (Abdel-Monem et al., 2012; El-Sayed et al., 2016 and 2019). The homogenate was thoroughly vortexed for 5 min, centrifuged at $8000 \mathrm{rpm}$ for $10 \mathrm{~min}$, and the supernatant was used as the source of crude enzyme. The supernatant was fractionally concentrated with $20 \mathrm{kDa}$ cut-of dialysis membrane (Cat. \# 546-00051) against polyethylene glycol 6000. The enzyme preparations were purified by ion-exchange chromatography with DEAE-Sepharose column $(1.5 \times 40 \mathrm{~cm})$. The pre-equilibrated column was load with the crude protein; the enzyme fractions were eluted with Tris-HCl buffer of $\mathrm{NaCl}$ gradients $(100-300 \mathrm{mM})$ at $1 \mathrm{~mL} / \mathrm{min}$ flow rate. The activity and concentration of GPx fractions were determined as described above. The most active homogenous fractions were collected, purified by gel-filtration chromatography using Sephadex G100 column (El-Sayed et al., 2017).

The molecular homogeneity and subunit structure of the purified GPx was assessed by denaturing-PAGE (Laemeli, 1970). The entire molecular mass of the purified GPx was determined by Native-PAGE with slight modification. The native sample buffer containing $500 \mu \mathrm{g}$ of purified GPx were vigorously shacked for $2 \mathrm{~min}$, then loaded to the native-PAGE (10\%) (El-Sayed et al., 2017). Gel was running for $2 \mathrm{~h}$ at $4{ }^{\circ} \mathrm{C}$, washed with Tris-HCl buffer, and soaked in $50 \mathrm{~mL}$ of $\mathrm{ddH}_{2} \mathrm{O}$ containing $1 \mathrm{mM}$ cumene hydroxide and $1 \mathrm{mM} \mathrm{GSH}$, incubated for $2 \mathrm{~h}$ and $80 \mathrm{rpm}$ using shaker incubator. Gel was rinsed twice with distilled water and stained with $1 \%$ ferric chloride and $1 \%$ potassium ferricyanide solution, the developed blue-black band allocates the activity of GPx (Li et al., 2000).

\subsection{Active site mapping and catalytic identity of purified GPX}

The catalytic identity of purified S. boulardii GPx was determined using the different cationic inhibitors and amino acids suicide analogues (El-Sayed et al., 2016 and 2017). The enzyme preparation was demetallized by dialysis (Cat \# 546-00051, Wako Chem., USA) against 50 mM Tris-HCl buffer (pH 7.5) containing $1 \mathrm{mM}$ EDTA for $2 \mathrm{~h}$. The apo-enzyme was amended with different cations, such as $\mathrm{Ba}^{2+}, \mathrm{Fe}^{3+}, \mathrm{Ca}^{2+}, \mathrm{Hg}^{2+}, \mathrm{Fe}^{3+}, \mathrm{Al}^{3+}, \mathrm{Zn}^{2+}, \mathrm{Na}^{+}, \mathrm{Cu}^{2+}$, and $\mathrm{Na}^{+}$at 1 $\mathrm{mM}$ final concentration for $2 \mathrm{~h}$ at $4{ }^{\circ} \mathrm{C}$, then the substrate was added and the enzymatic activity was measured by the standard assay. The influence of suicide amino acid reactive analogues namely; hydroxylamine, guanidine thiocyanate, DTNB, MBTH, $\mathrm{H}_{2} \mathrm{O}_{2}$ and PMSF (1 mM final conc.) on the activity of purified GPx were assessed. The enzyme was amended with each compound for $2 \mathrm{~h}$, then the substrate was added, and the residual enzymatic activity was measured by the standard assay.

\section{Results And Discussion}

\subsection{Screening of the significant culturing factors affecting GSH production using PBD}

Most recent studies used genetically modified $E$. coli strains to maximize the GSH production, where GSH production reached 5870 and 15,210 mg/L (Wang et al., 2016; Zhang et al., 2016). However, GMOs is not usually accepted, especially in food products, which represent an important application field for GSH, as well as the problems concerning consumer acceptance. The GSH biosynthesis pathway has been elucidated; it includes a two-step enzymatic catalyzed process (Johnston and Bloch, 1951). Firstly, gamma-glutamyl cysteine is synthesized from L-cysteine and L-glutamic acid via gamma-glutamyl cysteine synthetase (GSH1); secondly, GSH synthetase (GSH2) adds glycine to the C-terminal of gamma-glutamyl cysteine. The goal of the biotechnological production of GSH is to achieve a high total GSH through increasing the GSH content (intracellular) and/or the cell biomass. Although $S$. boulardii is a variety of $S$. cerevisiae, it differs from S. cerevisiae in its taxonomic, metabolic, and genetic properties (Mitterdorfer et al., 2002; Edwards-Ingram et al., 2007; Lei et al., 2016). Therefore, it is interesting to study the culture conditions for GSH production by S. boulardii. YMP medium components such as, glucose, yeast extract, peptone and malt extract were investigated. Glucose is the carbon and energy source, while the yeast extract supplies vitamin B complex, other growth factors, which is needed to generate enough biomass (Lorenz et al., 2016). Peptone serves as a source of nitrogen, carbon, and essential nutrients, while malt extract represents an additional source of carbon. Since GSH is a tripeptide, hence, its production has close relationship with certain intracellular amino acids, particularly amino acids composing it (Penninckx, 2002). Therefore, the three amino acids ( $\mathrm{Y}$-Glutamic acid, L-Cysteine and Glycine) could be important factors affecting its biosynthesis. Wang et al. (2012) reported that cysteine and glycine play a significant role in the synthesis of GSH. Likewise, the PBD analysis represented by Pareto-chart (Fig. 1) shows that cysteine is the key amino acid in the GSH production by $S$. boulardii. However, both glutamic acid and glycine have minor effects on GSH production by S. boulardii as shown from their high $p$-values and these results (Table 1) are in accordance with that obtained by Alfafara et al. (1992) and Wen et al. (2004). All literature data related to the production of GSH by yeasts reported that both cysteine and glycine significantly affected the GSH accumulation, while, glutamic acid did not (Wen et al., 2005). In our study, only cysteine significantly affected the GSH production (Table 1 and Figure 1).

PBD was used to screen the factors affecting GSH production by $S$. boulardii, results in Table (1) shows that there was a variation in the GSH production, which indicates the importance of studying the medium composition to obtain higher GSH productivity. Maximum GSH\% of 2.274 was obtained in the $8^{\text {th }}$ trial run, whereas, minimum GSH\% of 0.578 was obtained in the $22^{\text {nd }}$ trial run. This improvement was achieved on using glucose (70 g/L), yeast extract and peptone $(12 \mathrm{~g} / \mathrm{L})$, malt extract $(0 \mathrm{~g} / \mathrm{L}), \mathrm{pH}(3)$, temperature $\left(37^{\circ} \mathrm{C}\right)$, cysteine and glycine $(10 \mathrm{mM})$, glutamic acid $(0 \mathrm{mM})$, agitation rate $(300 \mathrm{rpm})$, culture volume $(25 \mathrm{~mL})$ and cultivation period $(24 \mathrm{~h})$. Also, the main effects of the examined variables on $\mathrm{GSH}$ production were calculated and graphed as a Paretochart (Fig. 1), which displayed the magnitude of each estimate and showed the ranking of the variable estimates. The effects of these variables and their significance were estimated by their $p$-values (Table 1). $P$-value $<0.05$ indicated that the influence of the variable was significant. Experimental data (Table 1 and Fig. 1) shows that 6 variables, including the time for cysteine addition, glucose, peptone, and yeast extract conc, temperature and agitation rate were identified as the significant variables. The $\mathrm{R}^{2}$ and the adjusted $\mathrm{R}^{2}$ values of the model are $95.56 \%$, and $93.63 \%$, respectively, indicating a high correlation. The 
best obtained results of both the yeast biomass and the GSH content revealed that the fermentation conditions that maximum cell growth did not exactly correspond to the best one found for high GSH production. The obtained results revealed that the optimum pH for high GSH production was 5.5 , where $S$. boulardii could tolerate gastric acidity (Buts, 1999) and could survive in wide $\mathrm{pH}$ range. S. boulardii produced better biomass and high $\mathrm{GSH}$ content at $31^{\circ} \mathrm{C}$; and these results are consistent with that of Du et al. (2012). Adequate oxygen can initiate the strain growth (Du et al., 2012) and consequently GSH production. The high $p$-value of 0.967 and 0.077 for the medium volume and incubation period, respectively, suggesting their insignificance effect on the GSH production; whereas the agitation rate (Table 1 and Fig. 1 ) has a low $p$-value (0.019) indicating its significant effect.

\subsection{The effect of addition time of cysteine}

The addition of the precursor amino acids, such as cysteine, glycine and glutamate was investigated by many researchers to increase the intracellular GSH content (Alfafara et al., 1992 a and b; Wang et al., 2012; Schmacht et al., 2017), and it was concluded that cysteine represents the key amino acid for GSH production and is the most common inducer for GSH overproduction (Schmacht et al., 2017). It is important to find out the optimal concentration of cysteine because this amino acid is the substrate of gamma-glutamyl cysteine synthetase; which is the first enzyme committed in GSH biosynthesis, however, at the same time, cysteine can act as growth inhibitor. Nevertheless, applying a post-growing procedure, its negative effect can be countered (Li et al., 2004; Wang et al., 2007).

To modulate the GSH metabolism in the fermentation process, it was necessary to investigate the appropriate time for the addition of cysteine. Therefore, 19 experiments were carried out for cysteine addition at $0,2,4,6,8,10,12,14,16,18,20,22,24,26,28,30,32,34$ and 36 h of growth using PBD design (Experiment no. 5). Results obtained (Fig. 2) shows that cysteine addition after 8-14 h of incubation had significant effect on GSH content with a maximum value of $235 \mathrm{mg} / \mathrm{L}$ after $8 \mathrm{~h}$. It could be concluded that cysteine worked well on the rapidly growing cell, which was in accordance with that obtained by Alfafara et al. (1992 a and b) and Liang et al. (2009), who reported that, the optimal time for GSH addition is during the stationary phase of $S$. cerevisiae, and that cysteine was the only amino acid that can enhance GSH production.

\subsection{Central Composite Rotatable Design (CCRD), model fitting and ANOVA}

Response surface methodology (RSM) use quantitative data to build an empirical model that describes the relationship between each factor investigated and the response. This model considers the effects of each factor, interactions between factors, and curvature (Myers et al., 2016). CCRD is the most popular class of second-order designs and widely used in RSM. Based on the PBD and the cysteine addition experiments, a CCRD experimental design was carried out to provide a proper model for the optimization of GSH production by $S$. boulardii, with 4 factors (glucose, yeast extract, peptone and cysteine concentrations) at 5-levels with cysteine addition after $8 \mathrm{~h}$ post-inoculation or at zero time. Results in Table (1) shows that GSH was increased from $218 \mathrm{mg} / \mathrm{L}$ to $559 \mathrm{mg} / \mathrm{L}$ by the addition of cysteine $8 \mathrm{~h}$ post-inoculation as compared to its addition at zero time (Exp. No. 20), indicating that the addition time is a crucial factor affecting GSH production by S. boulardii. Udeh and Achremowicz (1997) reported that total GSH concentration obtained at the optimal conditions was 160 $\mathrm{mg} / \mathrm{L}$, which was nearly 2 -fold that of the control without cysteine addition. Similarly, Lorenz et al. (2015) reported that the duration of cysteine addition was 6 $\mathrm{h}$, and he developed a repeated fed-batch procedure using cysteine $(0.40 \mathrm{~mol} / \mathrm{mol})$, to obtain a high biomass of $84.2 \mathrm{~g} / \mathrm{L}$ and GSH content of $1.3047 \mathrm{~g} / \mathrm{L}$ using S. cerevisiae Sa-07346. An analysis of variance (ANOVA) was used to determine whether the constructed model was adequate to describe the observed data (Table 1). The coefficient of determination $\left(R^{2}\right)$ indicates the percentage of the variability of the optimization parameters that is elucidated by the model. The response equation in which the parameters were fitted and interactions between them were determined as a quadratic equation (Equation 3 ) was as follows:

\section{Total GSH $(Y)=-0.424+0.00525 X_{1}+0.0373 X_{2}+0.0448 X_{3}+0.1732 X_{4}-0.000041 X_{1}^{2}-0.001231 X_{2}^{2}-0.001314 X_{3}^{2}-0.01377 X_{4}^{2}$ $+0.000107 X_{1} * X_{2}+0.000022 X_{1} * X_{3}-0.000322 X_{1} * X_{4}-0.000694 X_{2} * X_{3}-0.001833 X_{2} * X_{4}-0.002292 X_{3} * X_{4}$ (Equation 3)}

This equation revealed that cysteine concentration was the most significant factor as it shows a regression coefficient of 0.1732 , followed in order, by peptone concentration (0.0448), yeast extract (0.0373) and glucose (0.00525), exerting a statistically significant overall effect $(p$-value $<0.05)$ on the response. In addition, a positive sign represents a synergistic effect, whereas a negative one indicates an antagonistic effect.

From industrial perspective, total GSH ( $\mathrm{g} / \mathrm{L})$ was selected in this study, so media components were optimized with respect to total GSH as a response. CCRD results (Table 1) showed that the fermentation components formula that maximized cell growth (CDW) did not support the GSH accumulation. Run 23 showed the maximum cellular growth represented by CDW of $12.74 \mathrm{~g} / \mathrm{L}$, accompanied by low GSH production $(0.324 \mathrm{~g} / \mathrm{L})$ as compared with other runs in the design. On the other hand, run 29 showed the highest GSH production ( $0.552 \mathrm{~g} / \mathrm{L})$ accompanied by CDW of $10.66 \mathrm{~g} / \mathrm{L}$. The GSH content was almost doubled from 0.212 to $0.552 \mathrm{~g} / \mathrm{L}$, and its percentage (2.448 to 5.178 ) by cysteine addition $8 \mathrm{~h}$ post-inoculation, as compared to cysteine addition at zero time. The GSH concentration decreased when L-cysteine concentration was decreased, as indicated by the positive sign in the equation. These results are consistent with those of Wen et al. (2004 and 2005). It was reported that cysteine addition during the fermentation course promotes the increase of the GSH concentration. The increased activity of GSH synthetase upon cysteine addition may account to the increased conversion of Y-glutamyl cysteine to GSH (Santos et al., 2007; Wang et al., 2012). On the contrary, Fig. (3) shows that when cysteine was increased from $1 \mathrm{mM}$ to $3.75 \mathrm{mM}$, the GSH increased markedly to reach its maximum concentration of $0.559 \mathrm{~g} / \mathrm{L}$, and then decreased gradually when cysteine concentration was increased above $3.75 \mathrm{mM}$. The result of Alfafara et al. (1992 b) indicated that the positive effect on the specific GSH production rate was obtained when the cysteine concentration was above 3 mM. Results in Fig. (3), shows that when cysteine concentration was $5.12 \mathrm{mM}$, the GSH was decreased to $0.523 \mathrm{~g} / \mathrm{L}$. This can be explained by the inhibitory effect of cysteine on the yeast growth which was reflected by a decrease in its CDW. This was also confirmed by the reduction in yeast biomass when cysteine was added at zero time (Table 1).

The effect of glucose, cysteine, yeast extract and peptone concentrations and their interactive effects on GSH production were shown in Fig. (3) and Table (1). The produced GSH remained relatively constant $(0.549$ and $0.559 \mathrm{~g} / \mathrm{L})$ when the yeast extract was increased from 9.5 to $12.25 \mathrm{~g} / \mathrm{L}$, respectively, before its slight reduction to $0.549 \mathrm{~g} / \mathrm{L}$ when the yeast extract was increased to $15 \mathrm{~g} / \mathrm{L}$ (Fig. 3 and Table 1). In contrast, Cha et al. (2004) reported that $0.204 \mathrm{~g} / \mathrm{L}$ of GSH 
was produced, when $30 \mathrm{~g} / \mathrm{L}$ of yeast extract was used in the fermentation medium. However, Zhang et al. (2007) optimized GSH production by S. cerevisiae using Uniform Experimental Design and $0.740 \mathrm{~g} / \mathrm{L}$ of GSH was produced with $3 \mathrm{~g} / \mathrm{L}$ yeast extract, in shake-flask culture. Similarly, changing the peptone concentration exerts the same effect, where GSH remained around $0.550 \mathrm{~g} / \mathrm{L}$ when the peptone concentration increased from 8.3 to $11.3 \mathrm{~g} / \mathrm{L}$ (Fig. 3). Overall, the optimization plot of CCRD model predicted that GSH was to be $0.559 \mathrm{~g} / \mathrm{L}$ when using the optimal growth medium of $69.32 \mathrm{~g} / \mathrm{L} \mathrm{glucose}, 12.21 \mathrm{~g} / \mathrm{L}$ yeast extract, $11.12 \mathrm{~g} / \mathrm{L}$ peptone and $3.75 \mathrm{mM}$ cysteine (Equation 3). While, the experimental result gave a yield of $0.544 \mathrm{~g} / \mathrm{L} \mathrm{GSH}$, which was very close to the predicted one using CCRD analysis and close to the best trial (Run no. 20) in Table (1). The comparison of the predicted and experimental values showed good correlation between them, implying that the empirical model derived from CCRD can be used adequately to describe the relationship between all tested reaction parameters and the biosynthesis of GSH by $S$. boulardii. Hence, this model could then be used to predict GSH production, within the experimental range.

\subsection{The Effect of using baffled flasks on GSH production}

Shake-flask design is particularly important as it determines the performance of microbial culture in terms of produced GSH by establishing oxygen transfer conditions and hydrodynamics (Li et al., 2013). PBD and CCRD experiments were carried out in unbaffled conventional Erlenmeyer flasks. Several modifications to the conventional Erlenmeyer flasks have been proposed to improve mass transfer; nevertheless, the simplest and more effective one has been the baffling of the flasks. The comparison between unbaffled and baffled flasks emphasizes the advantages of efficient mass transfer and distinctive shear property in baffled flasks ( $\mathrm{Li}$ et al., 2013). The experiment was carried out using all the optimized conditions obtained from the CCRD analysis which are; glucose $69 \mathrm{~g} / \mathrm{L}$, yeast extract $12 \mathrm{~g} / \mathrm{L}$, peptone $11 \mathrm{~g} / \mathrm{L}$, cysteine $3.75 \mathrm{mM}$ added after $8 \mathrm{~h}$ of incubation, temperature was set at $31{ }^{\circ} \mathrm{C}$, agitation rate at $225 \mathrm{rpm}$, initial pH of 5.5 and incubation period of $32 \mathrm{~h}$. When the experiment (Fig. 4). was repeated using the optimized conditions in baffled flasks, the GSH was increased to $730 \mathrm{mg} / \mathrm{L}$, which was 4.5 -fold that obtained in non-optimized YMP medium and 1.31-fold that obtained using unbaffled flasks; indicating that good aeration is an important factor in the biotechnological production process of GSH by S. boulardii. Similar results were reported for $C$. utilis, when the cysteine addition was combined with controlling the dissolved oxygen, thus promoted efficient GSH production (Liang et al., 2008).

\subsection{Amplification, sequencing, phylogenetic, in-silico analyses of $g s h 1$ and $g s h 2$ genes}

To confirm the capability of $S$. boulardii to synthesize the GSH; gsh1 and gsh2 genes were amplified, cloned, and sequenced. Based on the reported sequence in the GenBank database (NCBI, 2014)., the genomic DNA that encodes the two genes were amplified with two synthetic primers that contained the Spel and Bgll/ sites for the first gene (gsh1), and Sall and Bglll sites for the second gene (gsh2). Two size products (2.2 and $1.5 \mathrm{~kb})$ from the gsh1 and gsh2 genes, respectively, were detected and confirmed using agarose gel electrophoresis (Fig. 5). These products were inserted into the plasmid pGEM-T and E. coli JM109 recipient strain was transformed by the resultant recombinant plasmids forming new clones. The original clone and the two subclones were subjected to automatic sequencing in Bionex Inc., Korea. The nucleotide sequences of gsh1 and gsh2 genes were submitted to the GenBank under the accession numbers: Bank It 2346245 BSeq\#1 MT583477, and Bank It 2346261 Gsh2 MT583478.

The obtained sequence data (Fig. 6) were further subjected to in-silico translation to obtain the uninterrupted ORF. Amino acid sequences were also subjected to BLAST analysis, which clearly revealed its identity to the amino acid sequences of gsh1p, gsh2p of other organisms. $S$. boulardii ( $g s h 1 p$ gene) and ( $g$ sh $2 p$ gene) showed high identity of $99 \%$ and $96 \%$ towards gsh1p of S. cerevisiae YJM1447 (AJR71399.1) and gsh2 gene of S. cerevisiae AWRI1631 (EDZ69442.1), respectively. The phylogenetic analysis was performed using MEGA5 and neighbor-joining method of 1000 bootstrap replicates. The gsh1p gene sequence of S. boulardii (Egy-B1 isolate) showed distinct clustering towards S. cerevisiae (EHN06463.1), whereas the sequence of gsh2p gene of S. boulardii (Egy-B1) isolate showed distinct clustering towards S. cerevisiae (AJT98762.1) (Fig. 6).

\subsection{Purification, and molecular subunit structure of $S$. boulardii GPX}

GPx was purified from $S$. boulardii by fractional concertation using dialysis membrane (20 kDa cut-off), followed by gel-filtration and ion-exchange chromatography (El-Sayed et al., 2019). After purification, GPx activity was increased by about 7.7 folds with 15.4 yield (Table 2). Overall, the specific activity of purified $S$. boulardii GPx was $445 \mu \mathrm{mol} / \mathrm{mg} / \mathrm{min}$, with protein concentration $0.2 \mathrm{mg} / \mathrm{L}$. The entire molecular mass and subunit structure of the purified GPx was about $80 \mathrm{kDa}$ and $35 \mathrm{kDa}$ as revealed from the native-PAGE and denaturing-PAGE, respectively (Fig. 7), ensuring the homodimeric identity of purified enzyme. Consistently, GPx with subunit structures 35-39 kDa was characterized by Mezzetti et al. (1990) and Brigelius-Flohé and Maiorino (2013).

\subsection{Biochemical properties of purified GPX}

The catalytic and structural identities of the purified GPx were assessed in response to various inhibitors and amino acids suicide analogues (El Baz et al., 2017). The enzyme preparation was demetallized by dialysis against $20 \mathrm{mM}$ Tris-HCl containing $1 \mathrm{mM}$ EDTA. The activity of holo-GPx was reduced from 445 $\mu \mathrm{mol} / \mathrm{mg} / \mathrm{min}$ to $180 \mu \mathrm{mol} / \mathrm{mg} / \mathrm{min}$ upon demetallization, (2.5-folds), ensuring the metalloproteinic identity of the enzyme (Table 3). The enzyme activity has been completely restored upon addition of $\mathrm{Se}^{+1}$ cations followed $\mathrm{Na}^{+1}$ suggesting the possibility of their implantation as enzyme cofactor. No obvious positive effect on the activity of Apo-GPx was noticed upon addition of divalent cations such as $\mathrm{Cu}^{+2}, \mathrm{Ba}^{+2}, \mathrm{Mg}^{+2}, \mathrm{Hg}^{+2}, \mathrm{Ca}^{+2}, \mathrm{Zn}^{+2}$ and trivalent cations Fe $\mathrm{Fe}^{+3}$ and $\mathrm{Al}^{+3}$. Similar results confirm the dependency of GPx from different organisms on the monovalent cations Se ${ }^{+1}$ as cofactor (Sabeh et al., 1993; Brigelius-Flohé and Maiorino, 2013; Mezzetti et al., 1990). The highest restoring activity of GPx in response to $\mathrm{Na}^{+1}$ might be due the molecular proximity of $\mathrm{Na}^{+1}$ with Se ${ }^{+1}$.

The active sites and catalytic identities of the purified S. boulardii GPx was evaluated from the amino acids suicide analogues, such as hydroxylamine, lodoacetate, 6-Diazo-5-Oxo-Norleucine, DTNB, MBTH, $\mathrm{H}_{2} \mathrm{O}_{2}$ and PMSF. The activity of purified GPx was reduced by 4-folds upon the addition of hydroxylamine, by 2-folds in response to DTNB, and by 1.7-folds in response to iodoacetate, MBTH, PMSF and 6-Diazo-5-Oxo-Norleucine, as compared to the holo-GPx activity. The strong reduction to the GPx activity in response to hydroxylamine and DTNB ensures the implication of surface lysine and cysteine residues on the active site domains of enzyme (El-Sayed et al., 2015 and 2016). While, the mild negative effect on the GPX activity by MBTH ensures the inaccessibility of

Page $7 / 20$ 
the asparagine, glutamine, and arginine residues for reactivity which might be due their presence in the enzyme core, with lower frequency of these residues on the enzyme surface. As well as, lower negative response of purified GPx in response to PMSF assures the limiting of accessibility of surface aspartic acid residues (El-Sayed et al., 2019). The catalytic efficiency affinity of the purified GPx from S. boulardii towards different substrates of proteineous amino acids, non-proteineous amino acids and tripeptides were assessed. The activity of GPx was measured as thiols peroxidase and deaminases activities (El-Sayed et al., 2016). Results obtained (Table 4), shows that the highest affinity of GPx was measured towards reduced GSH (100\%) followed by L-cysteine (95\%) and homocysteine (75\%) as substrates. The affinity of GPx towards these substrates could be due the presence of accessible reactive free thiols. However, the affinity of GPx towards oxidized GSH (GSSG), L-cystine, and homocystine as substrates was relatively low (15-23\%), that being reasonable due to the absence of free reactive thiols. The purified GPx displayed a very low deaminase activity towards the different tested substrate, especially to oxidized GSH (22\%), and the other tested amino acids. Furthermore, the kinetic properties of the purified GPx towards the reduced GSH, L-cysteine and homocysteine were determined based on thiols peroxidation. The highest affinity $\left(K_{m}\right)$ of purified GPx was reported for reduced GSH $\left(K_{m}=8 \mathrm{mM}\right)$, followed by L-cysteine $\left(K_{m}, 13 \mathrm{mM}\right)$, and oxidized GSH $\left(K_{m}, 39 \mathrm{mM}\right)$. As well as the highest turnover number $\left(\mathrm{K}_{c a t}\right)$ and catalytic efficiency for GPx was recorded for reduced GSH $\left(K_{c a t} 380 \mathrm{~s}^{-1}, K_{c a t} / K_{m}\right.$ $\left.208 \mathrm{mM}^{-1} \mathrm{~s}^{-1}\right)$ followed by L-cysteine $\left(K_{c a t} 218 \mathrm{~s}^{-1}, K_{c a t} / K_{m} 129 \mathrm{mM}^{-1} \mathrm{~s}^{-1}\right)$ and oxidized GSH (Table 4). Similar kinetic properties were reported for GPx from $S$. cerevisiae (Bai et al., 2004) and human (Liu et al., 2008).

\section{Conclusions}

The production of GSH-enriched yeasts for food applications might be the only way to achieve high intracellular GSH content as usually GMOs are not accepted. Molecular study was used to assure the genetic relatedness of $S$. boulardii isolate to the Saccharomyces spp. and the GSH enzyme production. This study revealed that the application of PBD and CCRD statistical analyses were efficient strategies to optimize the cultural conditions for GSH production by $S$. boulardii. Under the optimized conditions, the GSH was increased from $192 \mathrm{mg} / \mathrm{L}$ to $552 \mathrm{mg} / \mathrm{L}$ in conventional Erlenmeyer flasks. However, using baffled flasks, the GSH was significantly increased to $730 \mathrm{mg} / \mathrm{L}$. Optimum culture conditions for maximum GSH production were; glucose $69 \mathrm{~g} / \mathrm{L}$, yeast extract 12 $\mathrm{g} / \mathrm{L}$, peptone $11 \mathrm{~g} / \mathrm{L}$, agitation rate of $225 \mathrm{rpm}$, initial pH of 7 and $3.75 \mathrm{mM}$ cysteine added after $8 \mathrm{~h}$ of incubation at $31^{\circ} \mathrm{C}$. GPx was purified and characterized with 35-39 kDa subunits using SDS-PAGE. The activity of holo-GPx was reduced by 2.5 -folds upon demetallization, ensuring the metalloproteinic identity of this enzyme. The strong reduction to the GPx activity in response to hydroxylamine and DTNB ensures the implication of surface lysine and cysteine residues on the enzyme active site domains. The process strategy applied in this study showed the potential of using the GRAS S. boulardii with the aim of maximizing GSH production and the probiotic features of this specific yeast.

\section{Declarations}

\section{Conflict of Interest Statement}

All authors declare that there are no financial/commercial conflicts of interest.

\section{References}

Abdel-Monem, O.A., El-Baz, A.F., Shetaia, Y.M., El-Sabbagh, S.M. (2012). Production and application of thermostable cellulase-free xylanase by aspergillus fumigatus from agricultural wastes Industrial Biotechnology, 8:152-161

Alfafara, C. G., Kanda, A., Shioi, T., Shimizu, H., Shioya, S., Suga, K. I. 1992a. Effect of amino acids on glutathione production by Saccharomyces cerevisiae. Applied Microbiology and Biotechnology, 36, 538-540.

Alfafara, C., Miura, K., Shimizu, H., Shioya, S., Suga, K. I. 1992b. Cysteine addition strategy for maximum glutathione production in fed-batch culture of Saccharomyces cerevisiae. Applied Microbiology and Biotechnology, 37, 141-146.

Bachhawat, A.K., Ganguli, D., Kaur, J., Kasturia, N., Thakur, A., Kaur, H., Kumar, A. Yadav, A. 2009. Glutathione Production in Yeast, in: T. Satyanarayana, G. Kunze (Eds.), Springer, Dordrecht, Netherlands, pp. 259-280.

Bai, M., Zhou, J-M., Perrett, S. (2004). The Yeast Prion Protein Ure2 Shows Glutathione Peroxidase Activity in Both Native and Fibrillar Forms. The Journal of Biological Chemistry. 279:50025-50030.

Ballatori, N., Krance, S. M., Notenboom, S., Shi, S., Tieu, K., Hammond, C. L. 2009. Glutathione dysregulation and the etiology and progression of human diseases. Biological Chemistry, 390(3), 191-214.

Bradford, M.M. (1976) A Rapid and Sensitive Method for the Quantitation of Microgram Quantities of Protein Utilizing the Principle of Protein-Dye Binding. Analytical Biochem. 72, 248-254.

Brigelius-Flohé R, Maiorino M. (2013). Glutathione peroxidases. Biochim Biophys Acta. 1830:3289-303.

Buts, J.P. 1999. Mechanisms of action of biotherapeutic agents. In Biotherapeutic agents and infectious diseases: 27-46. Humana Press.

Cha, J. Y., Park, J. C., Jeon, B. S., Lee, Y. C., Cho, Y. S. 2004. Optimal fermentation conditions for enhanced glutathione production by Saccharomyces cerevisiae FF-8. Journal of Microbiology -Seoul, $42(1), 51-55$. 
Cui, X., Wan, J., Zhang, X., Wu, H., Li, Z., Ye, Q. 2019. Efficient glutathione production in metabolically engineered Escherichia coli strains using constitutive promoters. Journal of Biotechnology, 289, 39-45.

Dan, L.I.U., Yiman, Q.I., Ning, Z.H. A.O., Youfang, C.A.O., Junnan, X.U., Mingtao, F.A.N. 2020. Multivariate analysis reveals effect of glutathione-enriched inactive dry yeast on amino acids and volatile components of kiwi wine. Food Chemistry, 127086.

Du, L. P., Hao, R. X., Xiao, D. G., Guo, L. L., Gai, W. D. 2012. Research on the Characteristics and Culture Conditions of Saccharomyces boulardii. In: Advanced materials research, Vol. 343, pp. 594-598. Trans Tech Publications Ltd.

Edwards-Ingram, L., Gitsham, P., Burton, N., Warhurst, G., Clarke, I., Hoyle, D., Stateva, L. 2007. Genotypic and physiological characterization of Saccharomyces boulardii, the probiotic strain of Saccharomyces cerevisiae. Appl. Environ. Microbiol., 73(8), 2458-2467.

El Baz, A.F., Shetaia, Y.M., Elkhouli R.R. 2011. Xylitol production by Candida tropicalis under different statistically optimized growth conditions. African Journal of Biotechnology, 10(68), $15353-15363$.

El Baz, A.F., Sorour, N.M., Shetaia, Y.M. 2016. Trichosporon jirovecii-mediated synthesis of cadmium sulfide nanoparticles. Journal of Basic Microbiology, $56(5), 520-530$.

El Baz, A.F., El-Enshasy, H.A., Shetaia, Y.M., Mahrous, H., Othman, N.Z., Yousef, A.E. 2018. Semi-industrial Scale Production of a New Yeast with Probiotic Traits, Cryptococcus sp. YMHS, Isolated from the Red Sea. Probiotics and Antimicrobial Proteins 10 (1), 77-88.

El Baz, F.N., Gamal, R.F., ElBaz, A.F., Ibrahim, N.E., ElMekawy, A. (2017) Biochemical and biotechnological studies on a novel purified bacillus cholesterol oxidase tolerant to solvent and thermal stress. Biocatalysis and Biotransformation, 35: 205-214

El Baz, A.F., Shetaia, Y.M., Elkhouli, R.R. (2011) Kinetic behavior of Candida tropicalis during xylitol production using semi-synthetic and hydrolysate based media. African Journal of Biotechnology, 10: 16617-16625.

El Mekawy, A., Hegab, H.M., El-Baz, A., Hudson, S.M. (2013).Kinetic properties and role of bacterial chitin deacetylase in the bioconversion of chitin to chitosan. Recent Patents on Biotechnology, 7: 234-241.

El-Sayed, A.S.A., Abdel-Azim, S., Ibrahim H., Yassin, M.A., Abdel-Ghany S., Esener, S. Ali, GS (2015): Biochemical stability and molecular dynamic characterization of Aspergillus fumigatus cystathionine g-Lyase in response to various reaction effectors. Enzyme and Microbial Technology 81 : $31-46$.

El-Sayed, A.S.A., Hassan, A.E.A., Shindia, A.A., Mohamed, S.G., Sitohy, M.Z. (2016) Aspergillus flavipes L-methionine y-lyase dextran conjugates with enhanced structural proteolytic stability and anticancer efficiency. Journal of Molecular Catalysis: B-enzymatic, 133: S15-S24.

El-Sayed, A.S.A., Shindia, A.A., Abou-Zaid, A.A. Yassin, A.M. (2019): Aspergillus nidulans arginine deiminase- Dextran conjugates with enhanced molecular stability, proteolytic resistance, pharmacokinetic properties and anticancer activity. Enzyme and Microbial Technology 131: 12: 109432

Fietto, J. L., Araújo, R. S., Valadão, F. N., Fietto, L. G., Brandão, R. L., Neves, M., Castro, I. M. 2004. Molecular and physiological comparisons between Saccharomyces cerevisiae and Saccharomyces boulardii. Canadian Journal of Microbiology, 50(8), 615-621.

Gushima, H., Yasuda, S., Soeda, E., Yokota, M., Kondo, M., Kimura, A. 1984. Complete nucleotide sequence of the E. coli glutathione synthetase gsh-II. Nucleic Acids Research, 12(24), 9299-9307.

Habenicht, A., Hille, S., Knöchel, W. 1993. Molecular cloning of the large subunit of glutathione synthetase from Xenopus laevis embryos. Biochimica et Biophysica Acta (BBA)-Gene Structure and Expression, 1174(3), 295-298.

Hassan, A., Sorour, N.M., El Baz, A.F., Shetaia, Y.M. 2019. Simple synthesis of bacterial cellulose/ magnetite nanoparticles composite for the removal of antimony from aqueous solution. International Journal of Environmental Science and Technology 16 (3), 1433-1448.

Hong, J. Y., Son, S. H., Hong, S. P., Yi, S. H., Kang, S. H., Lee, N. K., Paik, H. D. 2019. Production of $\beta$-glucan, glutathione, and glutathione derivatives by probiotic Saccharomyces cerevisiae isolated from cucumber jangajji. LWT, 100, 114-118.

Huang, C.S., He, W., Meister, A., Anderson, M.E. 1995. Amino acid sequence of rat kidney glutathione synthetase. Proceedings of the National Academy of Sciences, 92(4), 1232-1236.

Johnston, R.B., Bloch, K. 1951. Enzymatic synthesis of glutathione. J. Biol. Chem., 188, 221-240.

Khullar, S., Reddy, M.S. 2020. Arsenic toxicity and its mitigation in ectomycorrhizal fungus Hebeloma cylindrosporum through glutathione biosynthesis. Chemosphere, 240, 124914.

Laemmli, U. (1970) Cleavage of Structural Proteins during the Assembly of the Head of Bacteriophage T4. Nature 227, 680-685.

Lei, Z., Chen, H., Huang, D., Zhai, Y., Shu, G. 2016. Optimization of Medium Compositions for Saccharomyces Boulardii by Box-Behnken Design. Scientific Study \& Research. Chemistry \& Chemical Engineering, Biotechnology, Food Industry, 17(4), 405. 
Li, C., Xia, J.Y., Chu, J., Wang, Y.H., Zhuang, Y.P., Zhang, S.L. 2013. CFD analysis of the turbulent flow in baffled shake flasks. Biochemical Engineering Journal, 70, 140-150.

Li C, Deng X, Zhang W, Xie X, Conrad M, Liu Y, Angeli JPF, Lai L. (2019) Novel Allosteric Activators for Ferroptosis Regulator Glutathione Peroxidase 4. J Med Chem. 2019 Jan 10; 62(1):266-275.

Li, Y., Wei, G., Chen, J. 2004. Glutathione: a review on biotechnological production. Applied Microbiology and Biotechnology, 66.233-242.

Li, S., Yan, T., Yang, J-Q., Oberley, T.D., Oberley. L.W. (2000) The Role of Cellular Glutathione Peroxidase Redox Regulation in the Suppression of Tumor Cell Growth by Manganese Superoxide Dismutase. Cancer Res 60, 3927-3939.

Liang, G.B., Du, G.C., Chen, J. 2008. A novel strategy of enhanced glutathione production in high cell density cultivation of Candida utilis-cysteine addition combined with dissolved oxygen controlling. Enzyme and Microbial Technology, 42(3), 284-289.

Liang, G., Liao, X., Du, G., Chen, J. 2009. A new strategy to enhance glutathione production by multiple $\mathrm{H}_{2} \mathrm{O}_{2}$-induced oxidative stresses in Candida utilis. Bioresource Technology, 100, 350-355.

Liang, G., Mo, Y., Du, G. 2010. Optimization of sodium dedecyl sulfate (SDS) addition coupled with adenosine triphosphate (ATP) regeneration for glutathione overproduction in high density cultivation of Candida utilis. Enzyme and Microbial Technology, 46, 526-533.

Lienkamp, A.C., Heine, T., Tischler, D. 2020. Glutathione: a powerful but rare cofactor among actinobacteria. In: Advances in Applied Microbiology, Academic Press. Vol. 110, pp. 181-217.

Lorenz, E., Schmacht, M., Senz, M. 2016. Evaluation of cysteine ethyl ester as efficient inducer for glutathione overproduction in Saccharomyces spp. Enzyme and microbial technology, 93, 122-131.

Lorenz, E., Schmacht, M., Stahl, U., Senz, M. 2015. Enhanced incorporation yield of cysteine for glutathione overproduction by fed-batch fermentation of Saccharomyces cerevisiae. Journal of Biotechnology, 216, 131-139.

McFarland, L.V., Bernasconi, P. 1993. Saccharomyces boulardii'. A review of an innovative biotherapeutic agent. Microbial Ecology in Health and Disease, 6(4), 157-171.

Meister, A. Anderson, M.E. 1983. Glutathione. Annual review of biochemistry, 52(1), 711-760.

Mezzetti A, Di llio C, Calafiore AM, Aceto A, Marzio L, Frederici G, Cuccurullo F. Glutathione peroxidase, glutathione reductase and glutathione transferase activities in the human artery, vein and heart. J Mol Cell Cardiol. 1990 Sep;22(9):935-8.

Mitterdorfer, G., Mayer, H.K., Kneifel, W., Viernstein, H. 2002. Clustering of Saccharomyces boulardii strains within the species S. cerevisiae using molecular typing techniques. Journal of Applied Microbiology, 93(4), 521-530.

Mutoh, N., Nakagawa, C.W., Hayashi, Y. 1995. Molecular cloning and nucleotide sequencing of the Y-glutamylcysteine synthetase gene of the fission yeast Schizosaccharomyces pombe. The Journal of Biochemistry, 117(2), 283-288.

Mutoh, N., Nakagawa, C.W., Ando, S., Tanabe, K., Hayashi, Y. 1991. Cloning and sequencing of the gene encoding the large subunit of glutathione synthetase of Schizosaccharomyces pombe. Biochemical and Biophysical Research Communications, 181(1), 430-436.

Myers, R.H., Montgomery, D.C., Anderson-Cook, C.M. 2016. Response surface methodology: process and product optimization using designed experiments. John Wiley \& Sons.

NCBI Resource Coordinators, 2014. Database resources of the National Center for Biotechnology Information. Nucleic Acids Res. doi:10.1093/nar/gkv1 290.

Ohtake, Y., Watanabe, K., Tezuka, H., Ogata, T., Yabuuchi, S., Murata, K., Kimura, A. 1989. Expression of the glutathione synthetase gene of Escherichia coli B in Saccharomyces cerevisiae. Journal of Fermentation and Bioengineering, 68(6), 390-394.

Penninckx, M.J. 2002. An overview on glutathione in Saccharomyces versus non-conventional yeasts. FEMS yeast research 2(3), 295-305.

Perricone, N.V. 2011. "Topical Acyl Glutathione Formulations." U.S. Patent Application 12/647,629.

Plackett, R.L, Burman, J.P. 1946. The design of optimum multifactorial experiments. Biometrika 33(4):305-325

Prima, A., Hara, K. Y., Djohan, A. C., Kashiwagi, N., Kahar, P., Ishii, J., Ogino, C. 2017. Glutathione production from mannan-based bioresource by mannanase/mannosidase expressing Saccharomyces cerevisiae. Bioresource Technology, 245, 1400-1406.

Rahman I, Kode A, Biswas SK. Assay for quantitative determination of glutathione and glutathione disulfide levels using enzymatic recycling method. Nat Protoc. 2006;1(6):3159-65.

Sabeh F, Wright T, Norton S, J: Purification and Characterization of a Glutathione Peroxidase from the Aloe vera Plant. Enzyme Protein 1993; $47: 92-98$. 
Saing, T., Lagman, M., Castrillon, J., Gutierrez, E., Guilford, F. T., Venketaraman, V. 2016. Analysis of glutathione levels in the brain tissue samples from HIV-1positive individuals and subject with Alzheimer's disease and its implication in the pathophysiology of the disease process. BBA clinical, 6, 38-44.

Santos, L. O., Gonzales, T. A., Ubeda, B. T., Alegre, R.M 2007. Influence of culture conditions on glutathione production by Saccharomyces cerevisiae, Appl. Microbiol. Biotechnol., 77, 763-769.

Schmacht, M., Lorenz, E., Stahl, U., Senz, M. 2017. Medium optimization based on yeast's elemental composition for glutathione production in Saccharomyces cerevisiae. Journal of Bioscience and Bioengineering, 123(5), 555-561.

Shi, C., Wang, X., Xiao, Z., Wang, R., Qiao, Y., Kan, G. 2020. Cloning, characterization and expression analysis of glutathione S-transferase from the Antarctic yeast Rhodotorula mucilaginosa AN5. Protein Expression and Purification, 167, 105518.

Tietze, F. (1969). Enzymic method for quantitative determination of nanogram amounts of total and oxidized glutathione: Applications to mammalian blood and other tissues. Analytical Biochemistry. 27:502-522.

Udeh, K. O., Achremowicz, B. 1997. High-glutathione containing yeast Saccharomyces cerevisiae: optimization of production. Acta Microbiologica Polonica, 46(1), 105-114.

Wang, C., Zhang, J., Wu, H., Li, Z., Ye, Q. 2015. Heterologous gshF gene expression in various vector systems in Escherichia coli for enhanced glutathione production. Journal of Biotechnology, 214, 63-68.

Wang, D., Wang, C., Wu, H., Li, Z., Ye, Q. 2016. Glutathione production by recombinant Escherichia coli expressing bifunctional glutathione synthetase. Journal of Industrial Microbiology \& Biotechnology, 43(1), 45-53.

Wang, Y., Wang, D., Wei, G., Shao, N. 2012. Enhanced co-production of S-adenosylmethionine and glutathione by an ATP-oriented amino acid addition strategy. Bioresource Technology, 107, 19-24.

Wang, Z., Tan, T., Song, J. 2007. Effect of amino acids addition and feedback control strategies on the high-cell-density cultivation of Saccharomyces cerevisiae for glutathione production. Process Biochemistry, 42(1), 108-111.

Wang, Y., Wu, S., Liu, C., Lu, X., Chen, Z. 2018. Herba Gelsemii elegantis is detoxified by ramulus et folium Mussaendae pubescentis extract by modulating hepatic cytochrome P450 and glutathione S-transferase enzymes in rats. Experimental and Therapeutic Medicine, 15(1), $226-234$.

Wei, G., Li, Y., Du, G., Chen, J. 2003. Effect of surfactants on extracellular accumulation of glutathione by Saccharomyces cerevisiae. Process Biochemistry, 38(8), 1133-1138.

Wen, S., Zhang, T., Tan, T. 2004. Utilization of amino acids to enhance glutathione production in Saccharomyces cerevisiae. Enzyme and Microbial Technology, 35(6-7), 501-507.

Wen, S., Zhang, T., Tan, T. 2005. Optimization of the amino acid composition in glutathione fermentation. Process Biochemistry, 40(11), $3474-3479$.

Wu, G., Fang, Y. Z., Yang, S., Lupton, J. R., Turner, N. D. 2004. Glutathione metabolism and its implications for health. The Journal of nutrition, $134(3)$, 489-492.

Xiong, Z. Q., Guo, M. J., Guo, Y. X., Chu, J., Zhuang, Y. P., Zhang, S. L. 2009. Efficient extraction of intracellular reduced glutathione from fermentation broth of Saccharomyces cerevisiae by ethanol. Bioresource Technology, 100(2), 1011-1014.

Yoshida, H., Hara, K. Y., Kiriyama, K., Nakayama, H., Okazaki, F., Matsuda, F., Kondo, A. 2011. Enzymatic glutathione production using metabolically engineered Saccharomyces cerevisiae as a whole-cell biocatalyst. Applied microbiology and Biotechnology, 91(4), 1001-1006.

Zhang, J., Quan, C., Wang, C., Wu, H., Li, Z., Ye, Q. 2016. Systematic manipulation of glutathione metabolism in Escherichia coli for improved glutathione production. Microbial Cell Factories, 15(1), 38.

Zhang, T., Wen, S., Tan, T. 2007. Optimization of the medium for glutathione production in Saccharomyces cerevisiae. Process Biochemistry, 42(3), 454-458.

Zhang, Z., Schwartz, S., Wagner, L., Miller, W. 2000. A greedy algorithm for aligning DNA sequences. Journal of Computational Biology, 7(1-2), $203-214$.

\section{Tables}

Table (1). Factors and testing levels of Plackett-Burman Design (PBD) of GSH production by Saccharomyces boulardii, the response is represented by GSH percentage, GSH content and yeast biomass dry wt. with respect to their p-values. 


\begin{tabular}{|c|c|c|c|c|c|c|c|c|c|c|c|c|c|}
\hline $\begin{array}{l}\text { Experiment } \\
\text { No. }\end{array}$ & Variables & & & & & & & & & & & & Res \\
\hline & $\begin{array}{l}\text { Glucose } \\
(\mathrm{g} / \mathrm{L})\end{array}$ & $\begin{array}{l}\text { Yeast ext. } \\
(\mathrm{g} / \mathrm{L})\end{array}$ & $\begin{array}{l}\text { Peptone } \\
\text { (g/L) }\end{array}$ & $\begin{array}{l}\text { Malt } \\
\text { ext. } \\
(\mathrm{g} / \mathrm{L})\end{array}$ & $\mathrm{pH}$ & $\begin{array}{l}\text { Temp. } \\
\left({ }^{\circ} \mathrm{C}\right)\end{array}$ & $\begin{array}{l}\text { Cysteine } \\
(\mathrm{mM})\end{array}$ & $\begin{array}{l}\text { Glutamic } \\
(\mathrm{mM})\end{array}$ & $\begin{array}{l}\text { Glycine } \\
(\mathrm{mM})\end{array}$ & $\begin{array}{l}\text { Agitation } \\
\text { (rpm) }\end{array}$ & $\begin{array}{l}\text { Volume } \\
(\mathrm{mL})\end{array}$ & $\begin{array}{l}\text { Period } \\
\text { (h) }\end{array}$ & $\begin{array}{l}\text { GSt } \\
\text { (g/l }\end{array}$ \\
\hline 1 & $+1(70)$ & $-1(0)$ & $+1(12)$ & $+1(12)$ & $-1(3)$ & $-1(25)$ & $-1(0)$ & $-1(0)$ & $+1(10)$ & $-1(150)$ & $+1(100)$ & $-1(24)$ & 0.0 \\
\hline 2 & +1(70) & $+1(12)$ & $-1(0)$ & $+1(12)$ & $+1(8)$ & $-1(25)$ & $-1(0)$ & $-1(0)$ & $-1(0)$ & $+1(300)$ & $-1(25)$ & $+1(48)$ & 0.0 ! \\
\hline 3 & $-1(30)$ & $+1(12)$ & $+1(12)$ & $-1(0)$ & $+1(8)$ & $+1(37)$ & $-1(0)$ & $-1(0)$ & $-1(0)$ & $-1(150)$ & $+1(100)$ & $-1(24)$ & 0.01 \\
\hline 4 & $-1(30)$ & $-1(0)$ & $+1(12)$ & $+1(12)$ & $-1(3)$ & $+1(37)$ & $+1(10)$ & $-1(0)$ & $-1(0)$ & $-1(150)$ & $-1(25)$ & $+1(48)$ & $0.0^{-}$ \\
\hline 5 & $0(50)$ & $0(6)$ & $0(6)$ & $0(6)$ & $0(5.5)$ & $0(31)$ & $0(5)$ & $0(5)$ & $0(5)$ & $0(225)$ & $0(62.5)$ & $0(36)$ & 0.1 ! \\
\hline 6 & $+1(70)$ & $-1(0)$ & $-1(0)$ & $+1(12)$ & $+1(8)$ & $-1(25)$ & $+1(10)$ & $+1(10)$ & $-1(0)$ & $-1(150)$ & $-1(25)$ & $-1(24)$ & $0.1:$ \\
\hline 7 & $+1(70)$ & $+1(12)$ & $-1(0)$ & $-1(0)$ & $+1(8)$ & $+1(37)$ & $-1(0)$ & $+1(10)$ & $+1(10)$ & $-1(150)$ & $-1(25)$ & $-1(24)$ & 0.01 \\
\hline 8 & $+1(70)$ & $+1(12)$ & $+1(12)$ & $-1(0)$ & $-1(3)$ & $+1(37)$ & $+1(10)$ & $-1(0)$ & $+1(10)$ & $+1(300)$ & $-1(25)$ & $-1(24)$ & $0.1 !$ \\
\hline 9 & $+1(70)$ & $+1(12)$ & $+1(12)$ & $+1(12)$ & $-1(3)$ & $-1(25)$ & $+1(10)$ & $+1(10)$ & $-1(0)$ & $+1(300)$ & $+1(100)$ & $-1(24)$ & $0.1:$ \\
\hline 10 & $-1(30)$ & $+1(12)$ & $+1(12)$ & $+1(12)$ & $+1(8)$ & $-1(25)$ & $-1(0)$ & $+1(10)$ & $+1(10)$ & $-1(150)$ & $+1(100)$ & $+1(48)$ & 0.01 \\
\hline 11 & $+1(70)$ & $-1(0)$ & $+1(12)$ & $+1(12)$ & $+1(8)$ & $+1(37)$ & $-1(0)$ & $-1(0)$ & $+1(10)$ & $+1(300)$ & $-1(25)$ & $+1(48)$ & $0.0^{-}$ \\
\hline 12 & $-1(30)$ & $+1(12)$ & $-1(0)$ & $+1(12)$ & $+1(8)$ & $+1(37)$ & $+1(10)$ & $-1(0)$ & $-1(0)$ & $+1(300)$ & $+1(100)$ & $-1(24)$ & 0.0 ? \\
\hline 13 & $+1(70)$ & $-1(0)$ & $+1(12)$ & $-1(0)$ & $+1(8)$ & $+1(37)$ & $+1(10)$ & $+1(10)$ & $-1(0)$ & $-1(150)$ & $+1(100)$ & $+1(48)$ & $0.1^{\circ}$ \\
\hline 14 & $-1(30)$ & $+1(12)$ & $-1(0)$ & $+1(12)$ & $-1(3)$ & $+1(37)$ & $+1(10)$ & $+1(10)$ & $+1(10)$ & $-1(150)$ & $-1(25)$ & $+1(48)$ & 0.0 ? \\
\hline 15 & $-1(30)$ & $-1(0)$ & $+1(12)$ & $-1(0)$ & $+1(8)$ & $-1(25)$ & $+1(10)$ & $+1(10)$ & $+1(10)$ & $+1(300)$ & $-1(25)$ & $-1(24)$ & 0.0\{ \\
\hline 16 & $-1(30)$ & $-1(0)$ & $-1(0)$ & $+1(12)$ & $-1(3)$ & $+1(37)$ & $-1(0)$ & $+1(10)$ & $+1(10)$ & $+1(300)$ & $+1(100)$ & $-1(24)$ & 0.0 \\
\hline 17 & $-1(30)$ & $-1(0)$ & $-1(0)$ & $-1(0)$ & $+1(8)$ & $-1(25)$ & $+1(10)$ & $-1(0)$ & $+1(10)$ & $+1(300)$ & $+1(100)$ & $+1(48)$ & 0.08 \\
\hline 18 & $0(50)$ & $0(6)$ & $0(6)$ & $0(6)$ & $0(5.5)$ & $0(31)$ & $0(5)$ & $0(5)$ & $0(5)$ & $0(225)$ & $0(62.5)$ & $0(36)$ & 0.1 ! \\
\hline 19 & $+1(70)$ & $-1(0)$ & $-1(0)$ & $-1(0)$ & $-1(3)$ & $+1(37)$ & $-1(0)$ & $+1(10)$ & $-1(0)$ & $+1(300)$ & $+1(100)$ & $+1(48)$ & $0.0^{-}$ \\
\hline 20 & $+1(70)$ & $+1(12)$ & $-1(0)$ & $-1(0)$ & $-1(3)$ & $-1(25)$ & $+1(10)$ & $-1(0)$ & $+1(10)$ & $-1(150)$ & $+1(100)$ & $+1(48)$ & 0.0 ? \\
\hline 21 & $-1(30)$ & $+1(12)$ & $+1(12)$ & $-1(0)$ & $-1(3)$ & $-1(25)$ & $-1(0)$ & $+1(10)$ & $-1(0)$ & $+1(300)$ & $-1(25)$ & $+1(48)$ & 0.0 ! \\
\hline 22 & $-1(30)$ & $-1(0)$ & $-1(0)$ & $-1(0)$ & $-1(3)$ & $-1(25)$ & $-1(0)$ & $-1(0)$ & $-1(0)$ & $-1(150)$ & $-1(25)$ & $-1(24)$ & $0.0:$ \\
\hline$P$-value & 0.000 & 0.019 & 0.002 & 0.814 & 0.879 & 0.019 & 0.000 & 0.153 & 0.923 & 0.0141 & 0.967 & 0.077 & \\
\hline Source & $\begin{array}{l}\text { Sum of } \\
\text { squares }\end{array}$ & $\begin{array}{l}\text { Degree of } \\
\text { freedom }\end{array}$ & $\begin{array}{l}\text { Mean } \\
\text { square }\end{array}$ & $\begin{array}{l}P \text { - } \\
\text { value }\end{array}$ & & & & & & & & & \\
\hline $\begin{array}{l}\text { Regression } \\
\text { (SR) }\end{array}$ & 0.302709 & 14 & 0.021622 & 0.000 & & & & & & & & & \\
\hline $\begin{array}{l}\text { Residual } \\
\text { (S.E.) }\end{array}$ & 0.047167 & 47 & 0.001004 & & & & & & & & & & \\
\hline Total (ST) & 0.349876 & 61 & & & & & & & & & & & \\
\hline
\end{tabular}

Table 2: Overall purification profile of glutathione peroxidase from Saccharomyces boulardii

\begin{tabular}{|llllll|}
\hline Purification step & Total protein $(\mathrm{mg})$ & Total Activity $(U)$ & Specific activity $(\mu \mathrm{mol} / \mathrm{mg} / \mathrm{min})$ & Purification Fold & Yield \\
\hline Crude & 10 & 585 & 58.5 & 1 & 100 \\
\hline Dialysis by 20 kDa cut-off & 4.5 & 449 & 99.7 & 1.71 & 76.8 \\
\hline DEAE-Sepharose & 1.04 & 172 & 165.4 & 2.84 & 29.5 \\
\hline Sephadex G100 & 0.20 & 89 & 445 & 7.7 & 15.4 \\
\hline
\end{tabular}

Table 3: Relative activity of purified $S$. boulardii glutathione peroxidase in response to various inhibitors and amino acid suicide analogues 


\begin{tabular}{|llll|}
\hline & Conc. (mM) & $\begin{array}{l}\text { Specific activity } \\
(\mu \mathrm{mol} / \mathrm{mg} / \mathrm{min})\end{array}$ & Relative activity \\
\hline Holo- GPx & 0 & 445 & 100 \\
\hline Demetallized GP** & 0 & 180 & 40.4 \\
\hline $\mathrm{KCl}$ & 10 & 202 & 45.3 \\
\hline $\mathrm{BaCl}$ & 10 & 230 & 51.6 \\
\hline $\mathrm{HgCl} 2$ & 10 & 270 & 60.6 \\
\hline FeCl3 & 10 & 301 & 67.6 \\
\hline CaCl2 & 10 & 359 & 80.6 \\
\hline ZnCl2 & 10 & 389 & 87.4 \\
\hline CuSO4 & 10 & 469 & 105.3 \\
\hline AlCl & 10 & 296 & 66.5 \\
\hline SeCl2 & 10 & 458 & 102.9 \\
\hline NaCl & 10 & 398 & 89.4 \\
\hline MgSO4 & 10 & 260 & 58.4 \\
\hline Hydroxylamine & 20 & 110 & 24.7 \\
\hline lodoacetate & 20 & 254 & 57.2 \\
\hline 6-Diazo-5-Oxo-Norleucine & 20 & 268 & 58.3 \\
\hline DTNB & 20 & 203 & 45.7 \\
\hline MBTH & 5 & 260 & \\
\hline PMSF & 20 & & 50.5 \\
\hline
\end{tabular}

Table 4: Substrate specificity of the purified $S$. boulardii glutathione peroxidase

\begin{tabular}{|llll|}
\hline & Substrate Con. (mM) & SH peroxidase relative activity (\%) & Deaminase relative activity (\%) \\
\hline Reduced glutathione (GSH) & 10 & 100 & 12 \\
\hline Oxidized glutathione (GSSG) & 10 & 15 & 22 \\
\hline L-Cysteine & 10 & 95 & 16 \\
\hline L-Cystine & 10 & 23 & 9 \\
\hline Homocysteine & 10 & 75 & 6 \\
\hline Homocystine & 10 & 18 & 4 \\
\hline L-Methionine & 20 & 0 & 3 \\
\hline L- Asparagine & 20 & 0 & 8 \\
\hline L-Glutamine & 20 & 0 & 0 \\
\hline L-Phenylalanine & 20 & 0 & 4 \\
\hline L-Ornithine & 20 & 0 & 5 \\
\hline L-Arginine & 20 & 0 & 8 \\
\hline Bovine serum albumin & 5 & 16 & 9 \\
\hline
\end{tabular}

Table 5: Kinetics parameters of the purified S. boulardii glutathione peroxidase

\begin{tabular}{|lllll|}
\hline & $K_{m}(\mathrm{mM})$ & $V_{\max }(\mu \mathrm{mol} / \mathrm{mg} / \mathrm{min})$ & $K_{c a t}\left(\mathrm{~s}^{-1}\right)$ & $K_{\text {cat }} / K_{m}\left(\mathrm{mM}^{-1} \mathrm{~s}^{-1}\right)$ \\
\hline Reduced Glutathione (GSH) & 8 & 450 & 380 & 208 \\
\hline Oxidized Glutathione (GSSG) & 39 & 98 & 114 & 85 \\
\hline L-Cysteine & 13 & 320 & 218 & 129 \\
\hline
\end{tabular}




\section{Figures}

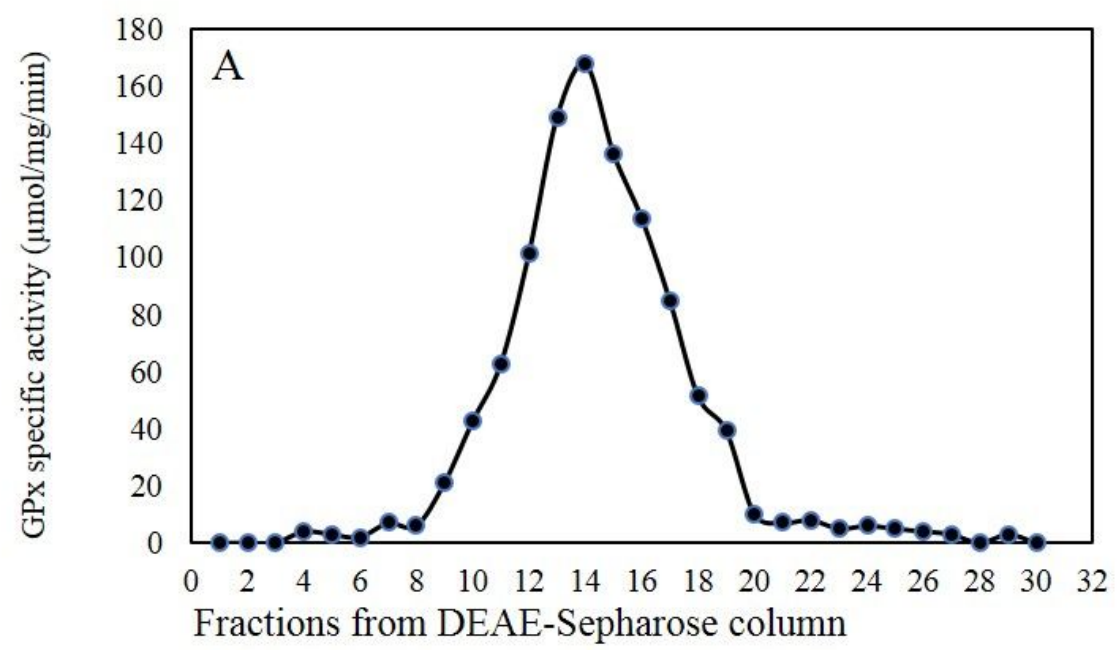

C

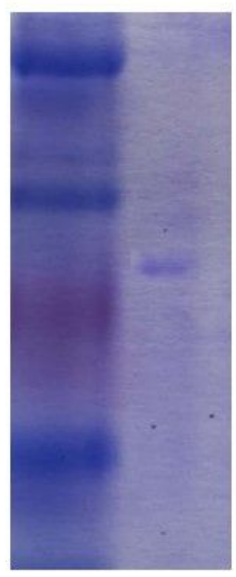

D

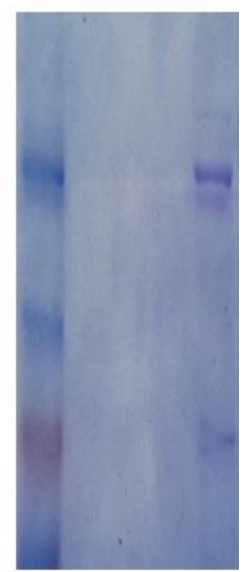

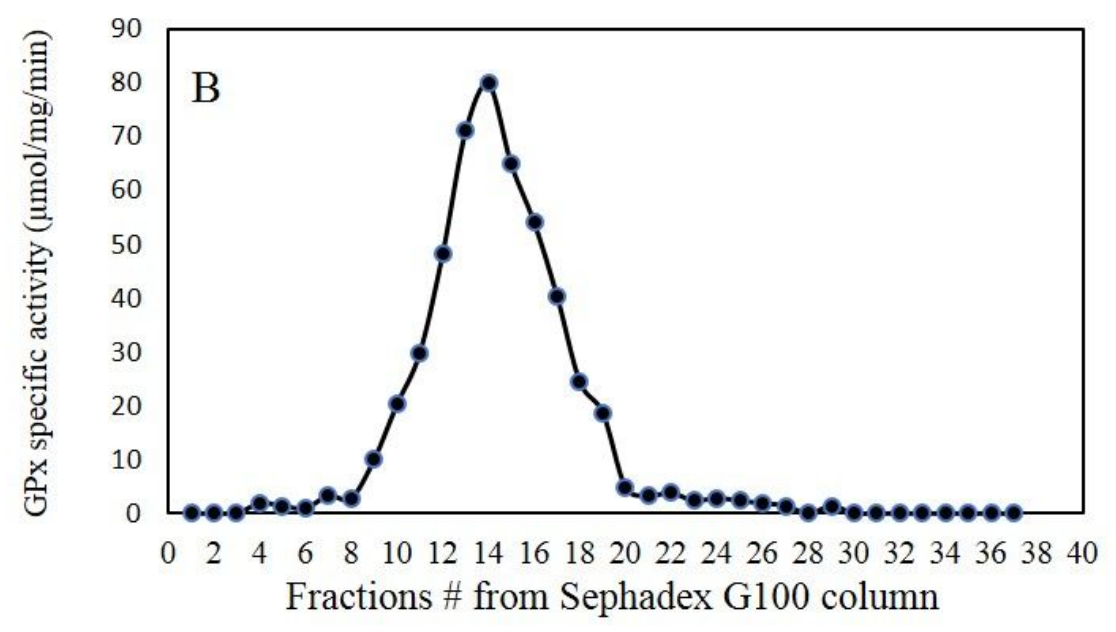

Figure 1

Pareto-chart rationalizing the effect of each variable on the production of GSH by S. boulardii using PBD. The vertical line defines the $95 \%$ confidence interval. 


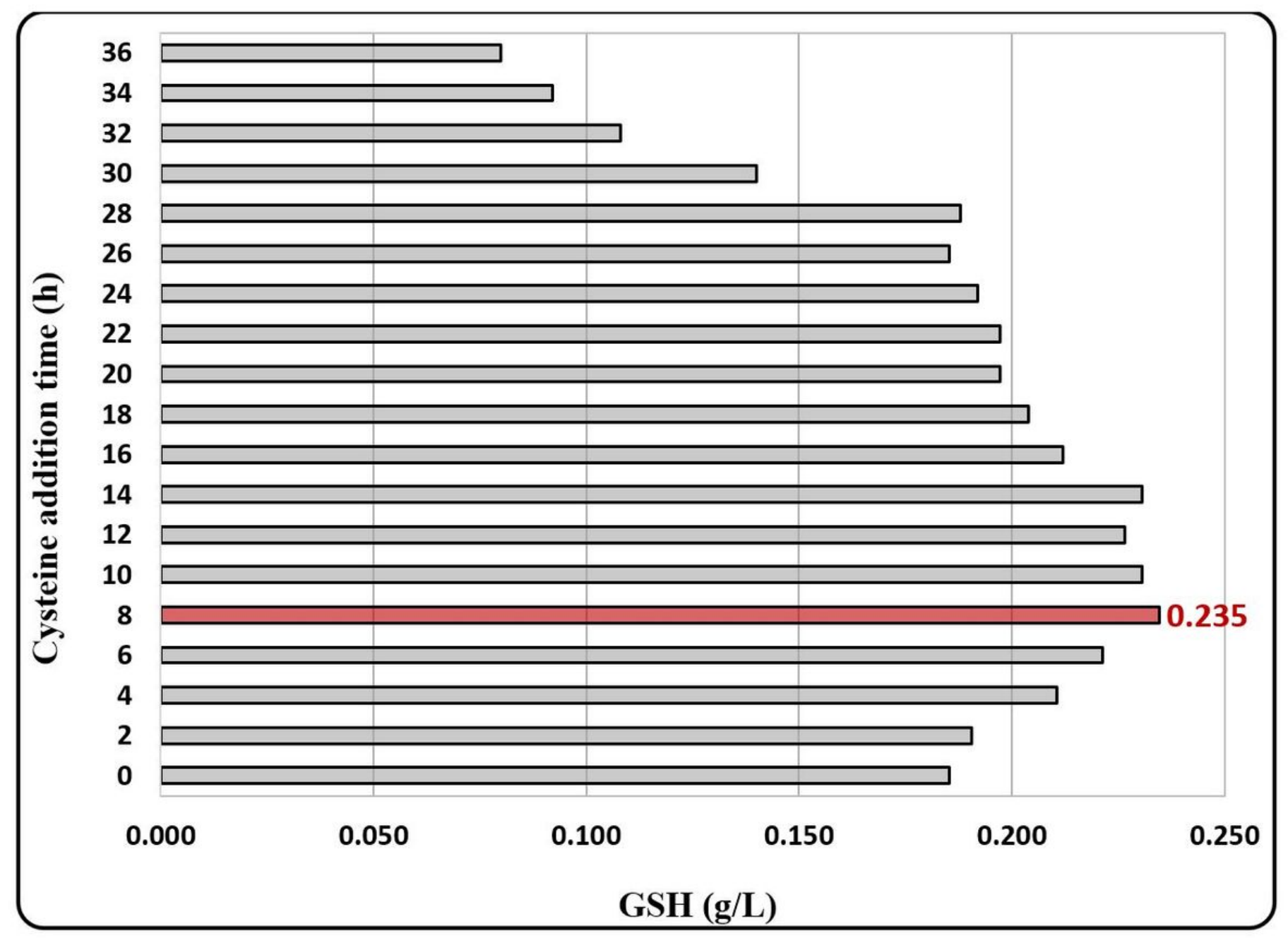

Figure 2

Effect of addition time of cysteine on the GSH production by S. boulardii. 

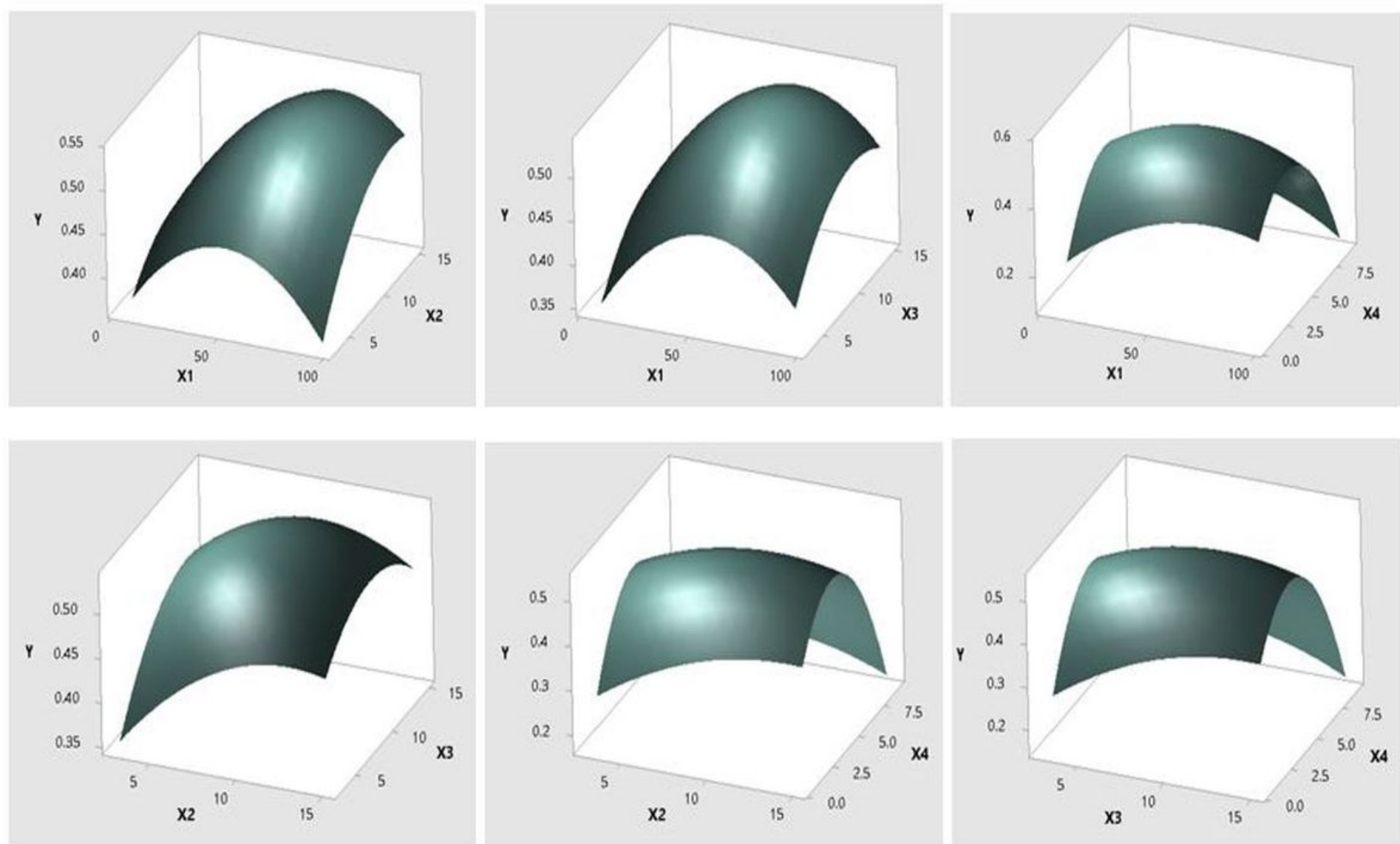

Figure 3

3D-response surface plot showing the effect of some factors and their interaction on GSH production by S. boulardii, (A) peptone conc., yeast extract conc., other variables are constant ( $52.5 \mathrm{~g} / \mathrm{L}$ glucose and $5 \mathrm{mM}$ cysteine); (B) cysteine conc., yeast extract conc., other variables are constant (52.5 g/L glucose and $9 \mathrm{~g} / \mathrm{L}$ peptone); (C) cysteine conc., peptone conc., other variables are constant, (52.5 g/L glucose and $9 \mathrm{~g} / \mathrm{L}$ yeast extract); ( $\left.\mathrm{A}^{\prime}\right)$ yeast extract conc., glucose conc.; (B') peptone conc., glucose conc.; and ( $\left.\mathrm{C}^{\prime}\right)$ cysteine conc., glucose conc. 


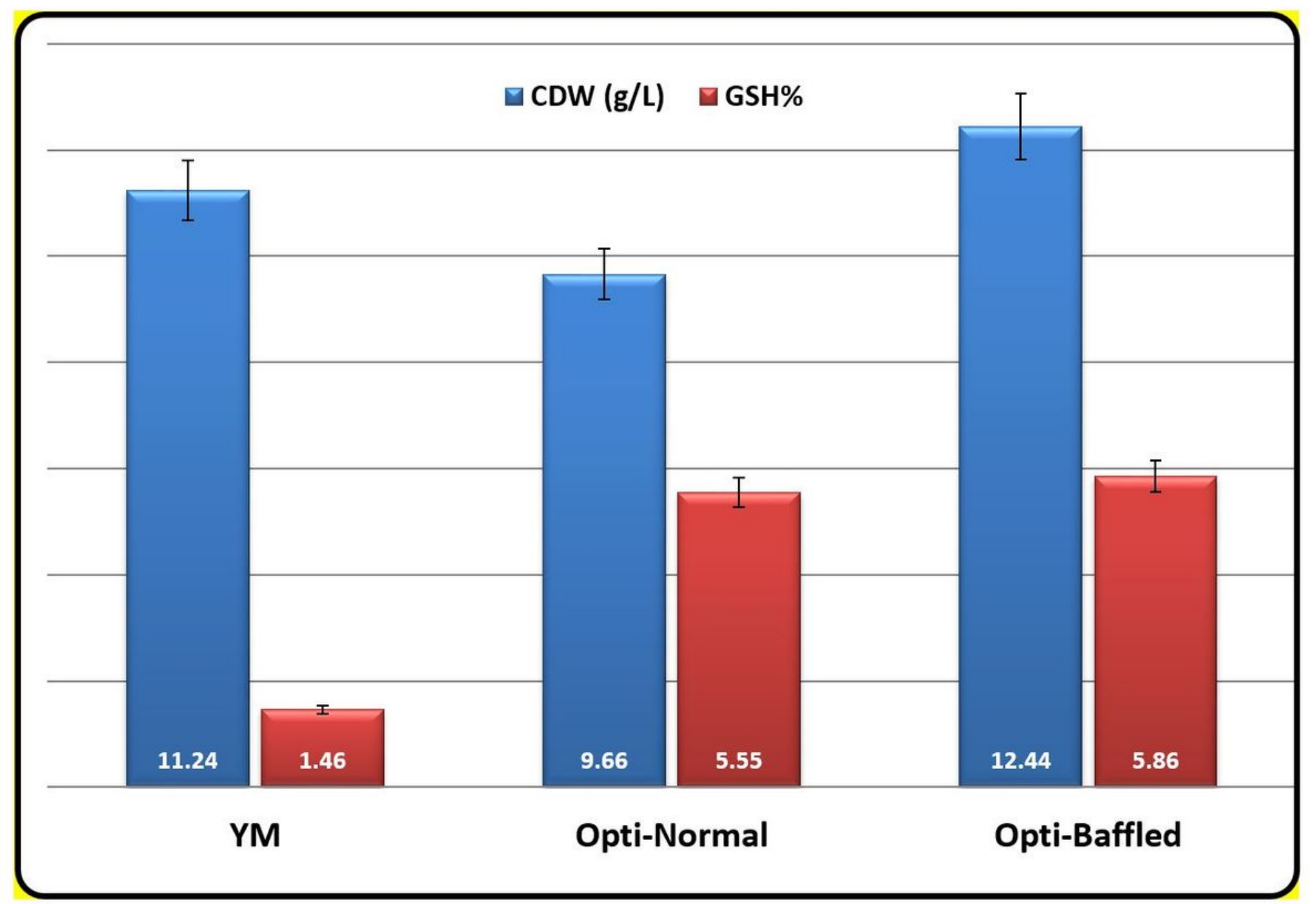

Figure 4

Effect of using baffled flasks on Cell Dry Weight (CDW) of S. boulardii and its production of GSH in Yeast Malt Peptone medium (YM), optimized medium in normal flasks (Opti-Normal) and optimized medium in baffled flasks (Opti-Baffled). 


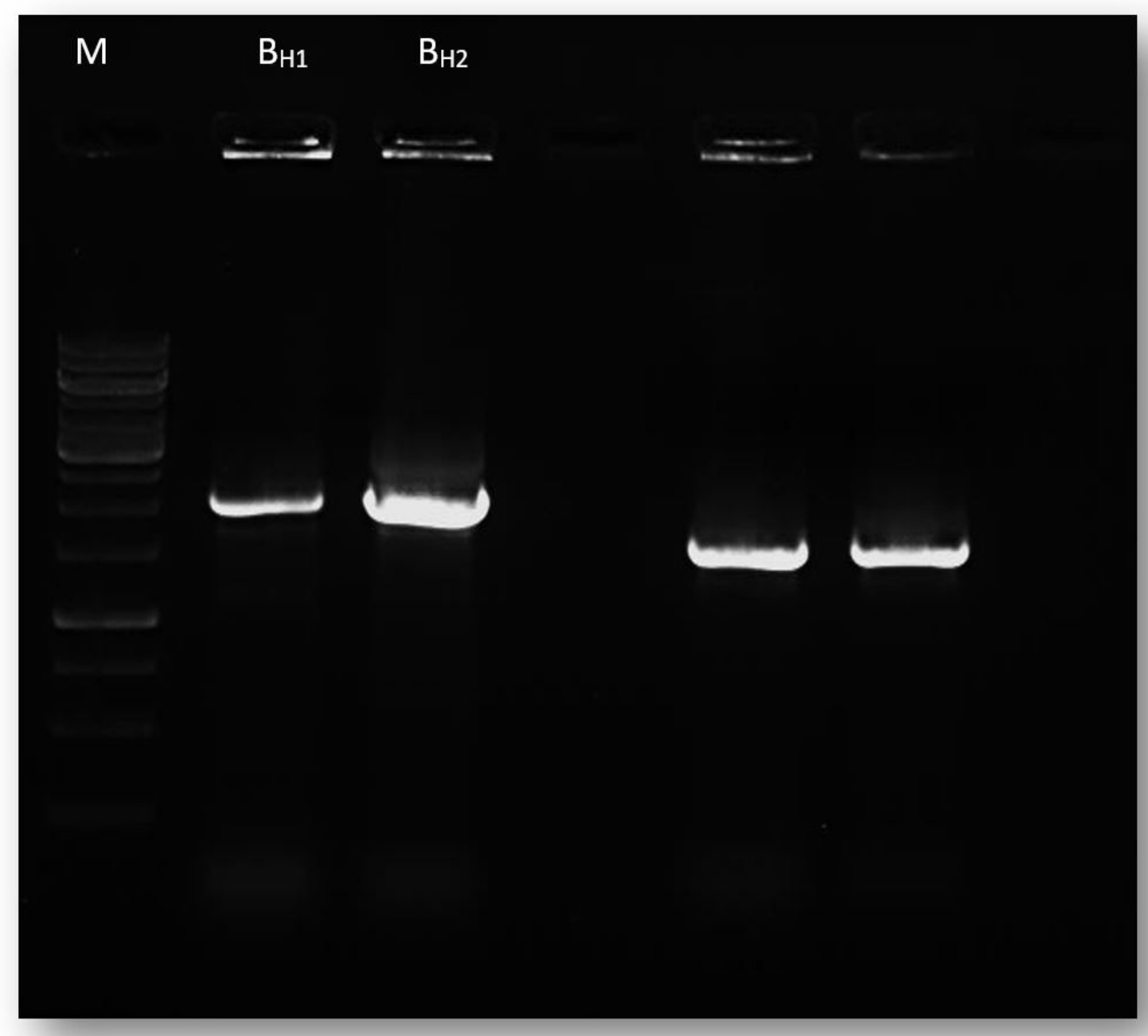

Figure 5

Specific PCR products using gsh1 and gsh2 primers $(\mathrm{BH} 1$ and $\mathrm{BH} 2)$ for the S. boulardii strain. 


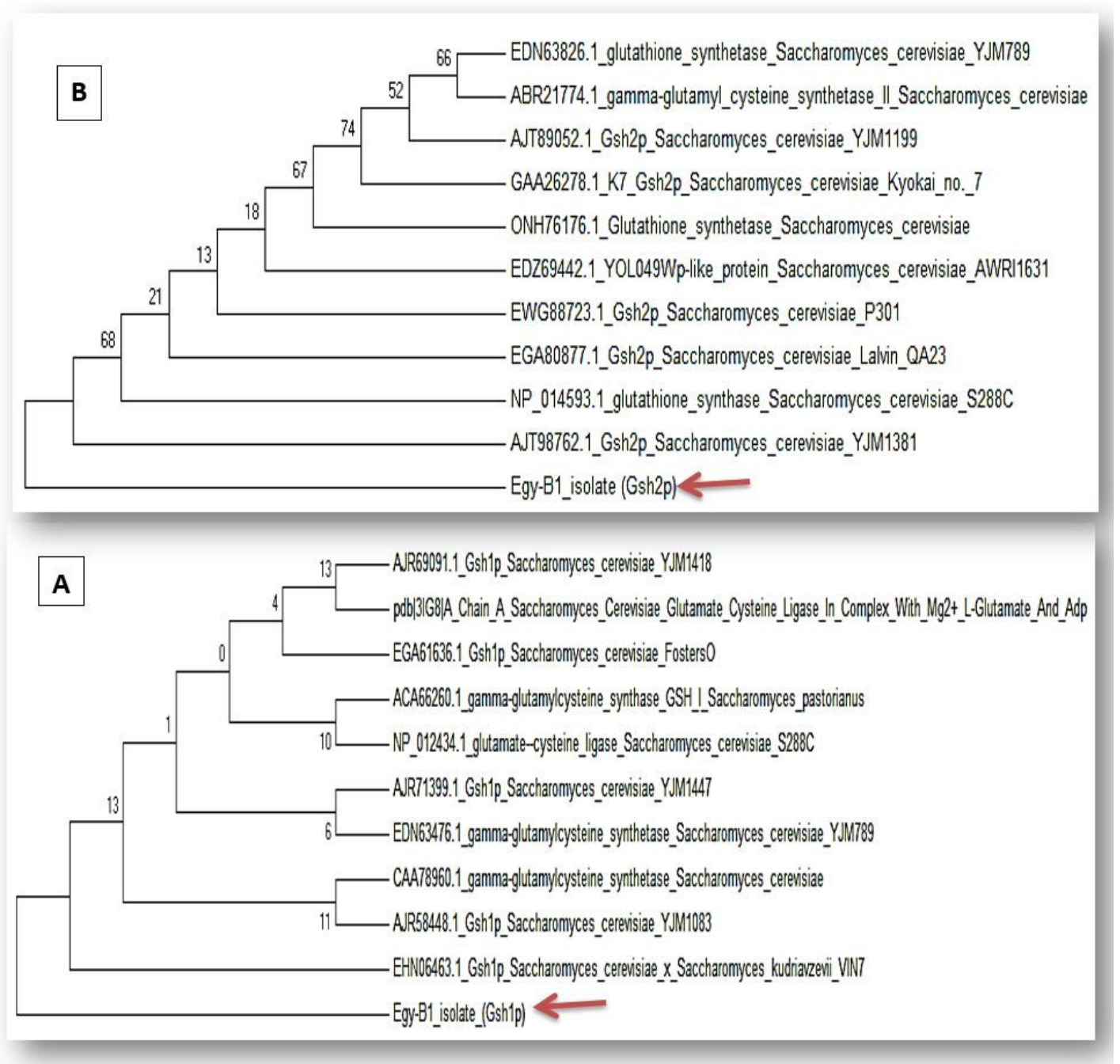

\section{Figure 6}

The phylogenetic analysis of Gsh1p (A) and Gsh2p (B) genes sequence of the Egy-B1 isolate along with their amino acid sequences retrieved from NCBI using MEGA 5 with neighbor-joining method using 1000 bootstrap replicates. 


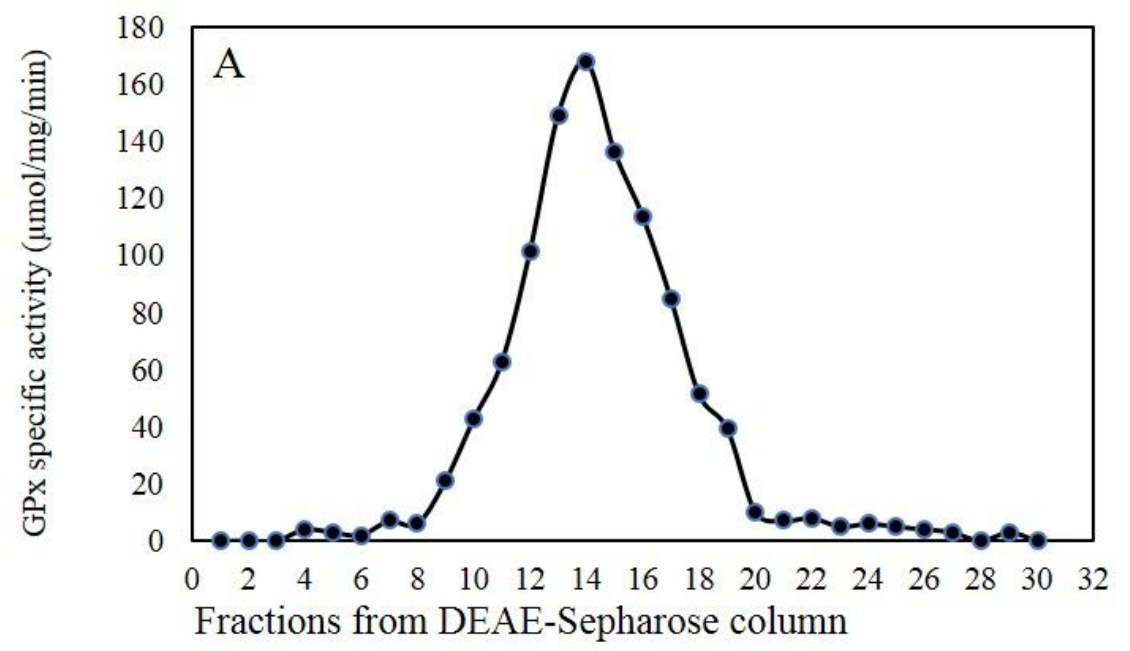

C

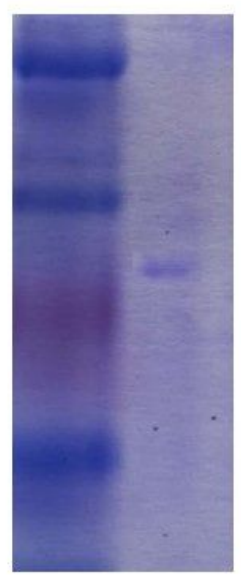

D

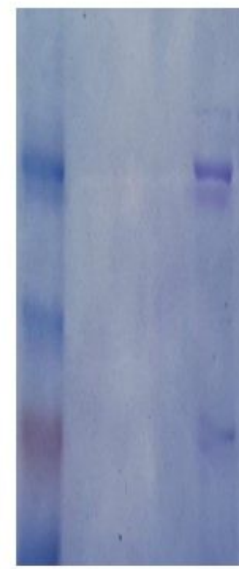

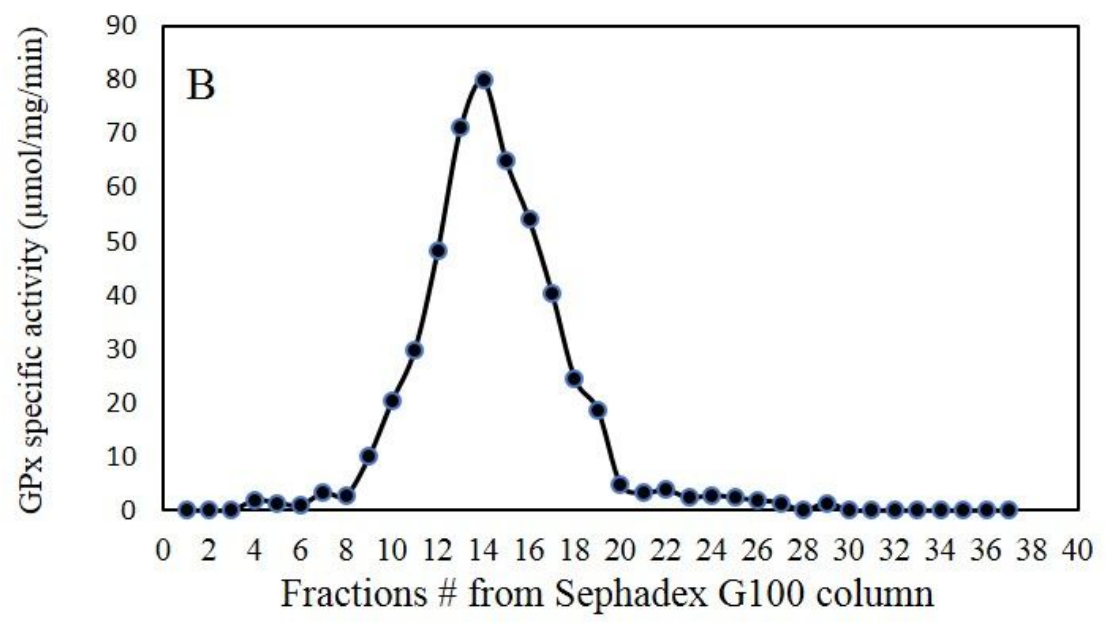

Figure 7

Purification and molecular subunit structure of glutathione peroxidase from S. boulardii. The deiminases were extracted and purified from the fungal pellets by gel-filtration and ion-exchange chromatography and their homogeneity were checked by denaturing and nondenaturing PAGE. The concentrated crude enzyme was fractionated on ion-exchange purification column (A), followed by Gel-filtration (B) chromatography. The most active fractions from the last chromatographic column was concentrated, and the enzyme subunit structure and entire molecular mass was determined from the SDS-PAGE (C) and NativePAGE (D). M, protein Marker (Cat. \# PG-PMT2962, 315-10 kDa). 